Article

\title{
Application of the Taguchi Method for Optimizing the Process Parameters of Producing Controlled Low-Strength Materials by Using Dimension Stone Sludge and Lightweight Aggregates
}

\author{
How-Ji Chen ${ }^{1}$, Hsuan-Chung $\operatorname{Lin}^{1}$ (D) and Chao-Wei Tang $2,3,4, *$ (D) \\ 1 Department of Civil Engineering, National Chung-Hsing University, No. 250, Kuo Kuang Road, \\ Taichung 402, Taiwan; hojichen@dragon.nchu.edu.tw (H.-J.C.); abb7028@gmail.com (H.-C.L.) \\ 2 Department of Civil Engineering and Geomatics, Cheng Shiu University, No. 840, Chengching Road, \\ Niaosong District, Kaohsiung 83347, Taiwan \\ 3 Center for Environmental Toxin and Emerging-Contaminant Research, Cheng Shiu University, No. 840, \\ Chengching Road, Niaosong District, Kaohsiung 83347, Taiwan \\ 4 Super Micro Mass Research and Technology Center, Cheng Shiu University, No. 840, Chengching Road, \\ Niaosong District, Kaohsiung 83347, Taiwan \\ * Correspondence: tangcw@gcloud.csu.edu.tw; Tel.: +886-7-735-8800
}

check for updates

Citation: Chen, H.-J.; Lin, H.-C.; Tang, C.-W. Application of the Taguchi Method for Optimizing the Process Parameters of Producing Controlled Low-Strength Materials by Using Dimension Stone Sludge and Lightweight Aggregates. Sustainability 2021, 13, 5576. https://doi.org/ $10.3390 /$ su13105576

Academic Editor: Sunkuk Kim

Received: 1 April 2021

Accepted: 15 May 2021

Published: 17 May 2021

Publisher's Note: MDPI stays neutral with regard to jurisdictional claims in published maps and institutional affiliations.

Copyright: (c) 2021 by the authors. Licensee MDPI, Basel, Switzerland. This article is an open access article distributed under the terms and conditions of the Creative Commons Attribution (CC BY) license (https:// creativecommons.org/licenses/by/ $4.0 /)$.

\begin{abstract}
In view of the increasing concerns over non-renewable resource depletion and waste management, this paper studied the development of low-density controlled low-strength material (CLSM) by using stone sludge and lightweight aggregates. First, the investigation was performed at a laboratory scale to assess the effects of the composition on the properties of the resulting low-density CLSM. The Taguchi method with an $L_{9}\left(3^{4}\right)$ orthogonal array and four controllable three-level factors (i.e., the stone sludge dosage, water to binder ratio, accelerator dosage and lightweight aggregate dosage) was adopted. Then, to optimize the selected parameters, the analysis of variance method was used to explore the effects of the experimental factors on the performance (fresh and hardened properties) of the produced low-density CLSM. The test results show that when the percentage of stone sludge usage was increased from $30 \%$ to $60 \%$, the initial setting time approximately doubled on average. Moreover, at the age of 28 days, the compressive strength of most specimens did not exceed the upper limit of 8.83 MPa stipulated by Taiwan's Public Construction Commission. Further, the material cost per cubic meter of the produced CLSM was about NT\$ 720.9 lower than that of the ordinary CLSM, which could reduce the cost by $40.6 \%$. These results indicate that the use of stone sludge as a raw material to produce CLSM could achieve environmental sustainability. In other words, the use of stone sludge and lightweight aggregates to produce low-density CLSM was extremely feasible.
\end{abstract}

Keywords: stone sludge; lightweight aggregates; controlled low-strength materials; Taguchi method

\section{Introduction}

The continuous progress of science and technology has improved social productivity and material standard of living, and has achieved unprecedented prosperity and development of human society. However, the widespread application of science and technology in various fields has also caused a certain degree of environmental pollution, ecological destruction, and resource scarcity, which may cause devastating potential threats to the entire earth of human life. According to the second edition of NACE [1], the total amount of waste generated by the economic activities of households and businesses in the EU in 2018 was 2.609 billion tons, and in 2008, the amount of recyclable waste was 202 million tons. In view of this, a key element of the EU's environmental policy is to manage waste in an environmentally sound manner and make full use of the auxiliary materials contained therein. Similarly, with the rise of interest in the concept of sustainable development and the awareness of environmental protection, it has become increasingly difficult to obtain 
raw materials for concrete production in Taiwan. For these reasons, Taiwan promulgated (amended on 21 January 2009) the Resource Recycling Act [2] on 3 July 2002, to reduce the use of natural resources, reduce waste generation, promote the recycling and reuse of materials, reduce the environmental load and build a society in which resources can be used continuously. Currently, the Ministry of Economic Affairs of the Republic of China in Taiwan has announced 57 types of industrial waste for reuse, which can be divided into engineering, agricultural and other uses. Among them, there are 22 types of recycling for engineering purposes (such as waste casting sand, stone sludge, stone waste, coal ash, waste wood, waste glass, waste pottery, waste porcelain, waste bricks, waste tiles, etc.). These can be recycled for the production of civil engineering and construction materials.

According to the definition of the American Concrete Institute (ACI), controlled lowstrength materials (CLSM) is a self-filling, self-leveling and cementitious material that is mainly used to replace traditional backfill soil and structural fillers. Generally, the compressive strength of CLSM at 28 days is $8.3 \mathrm{MPa}$ or lower [3]. Although CLSM's requirements for its constituent materials are not as strict as those of ordinary concrete materials, it provides suitable engineering characteristics at a lower cost for most needs and is in line with energy-saving and ecological benefits [4]. Essentially, CLSM has excellent rheological properties and anti-segregation ability, and it can be easily filled in a narrow excavation surface without any tamping. Moreover, CLSM has a low and sufficient loadbearing strength, which can facilitate future excavation [5-7]. Therefore, the application of CLSM has become more and more common in countries around the world and in Taiwan.

The stone processing industry is an important industry in Taiwan (with an annual output value of nearly 1.42 billion U.S. dollars), but the impact of its wastewater, solid waste and dust in the environment cannot be underestimated. In the cutting process of natural stone, a large amount of stone chips and waste will be produced. In order to cool the cutting saw blade, a large amount of cooling water must be used, resulting in a considerable amount of mud-like waste (a mixture wastewater and stone chips), which is called dimension stone waste mud. The dimension stone waste mud is discharged to the wastewater treatment plant, and the waste produced after sedimentation, separation and dehydration is called stone sludge. In Europe, the amount of annual stone sludge is estimated to be 5 million tons [8]. The annual output of Taiwan's stone sludge and stone waste exceeds 1.1 million tons [9], which in general comprises industrial wastes. However, due to the relatively low cost of the burial treatment of stone sludge or the poor marketing of resource-recycling products, the amount of resource treatment is quite limited, and the benefits of its resource application cannot be brought into full play.

Because concrete has the advantages of durability, fire resistance, high compression resistance, good shape ability, economy, etc., it is currently the most widely used man-made material. However, the production of cement is the main source of greenhouse gas emissions, which has severely damaged the earth's climate and environment and threatened the sustainable survival of mankind. From the perspective of maintaining the ecological sustainability of the natural environment and the overall economic benefits of society, actively developing alternative sources of construction materials to replace some of the traditional main sources is an important issue that cannot be delayed. In terms of the sustainable development of concrete materials, we can start with the design of materials and mix proportions. For example, the use of renewable resources to replace part of cement or aggregates will not only greatly contribute to energy saving and carbon reduction, but also improve the fresh property and durability of concrete materials. Martínez-García et al. [10] evaluated the viability of incorporating fine recycled concrete aggregates (FRCA) from urban demolition and construction waste for the manufacture of cement-based mortars. The results showed that the optimal percentage of substitution of fine natural aggregates for FRCA was $25 \%$ with respect to compressive and flexural strength tests. López Boadella et al. [11] analyzed the feasibility of using waste from a granite quarry to replace the micronized quartz in ultra-high-performance concrete (UHPC). The results showed that when the substitution rate was 35\%, the flexural strength and tensile strength increased, and the values obtained 
even for $100 \%$ substitution was acceptable. This confirmed that granite cutting waste instead of commonly used micronized quartz powder was a viable alternative to the expected more sustainable UHPC. Zamora-Castro et al. [12] reviewed the latest research on the performance of different sustainable concrete types. They recommend the use of standardized testing to ensure reliable results of the impact of sustainable materials on the physical and mechanical properties of concrete specimens. In addition, because recycled materials mixed into concrete showed high absorption capacity, it could cause workability problems of fresh concrete, thereby affecting its mechanical strength. Therefore, they recommend finding the best combination of materials from different sources to improve these properties of sustainable concrete. In addition, Chen et al. [13-15] used reservoir sediments, paper sludge and tile grinding sludge to produce lightweight aggregates, turning waste into renewable resources.

In order to achieve the purpose of waste reduction and resource reuse, renewable resources, and industrial wastes from all over the world have been used in large quantities in the production of CLSM, such as coal ash and new pozzolanic materials [16], cement kiln dust [17], stockpiled circulating fluidized bed combustion ashes [18], circulating fluidized bed combustion ash and recycled aggregates [19], bottom ash of municipal solid waste incinerator and water filter silt [20], solid wastes/byproducts from paper mills [21], circulating fluidized bed combustion ash [22,23], waste oyster shells [24], treated oil sand waste [25], alum sludge and green materials [26], waterworks sludge [27], water purification sludge [28], etc. Hung et al. [29] established a prediction model for the compressive strength and surface resistivity of controlled low-strength desulfurization slag. They suggested that expanding the use of unqualified raw materials and man-made waste as secondary raw materials could be one of the most important directions for creating a waste-free process to ensure the most reasonable use of natural resources and reduce the negative impact on environmental conditions. Park and Hong [30] analyzed the influence of the mixing conditions of wastepaper sludge ash (WPSA) on the strength and bearing capacity of controlled low-strength materials (CLSM). The results showed that CLSM and WPSA could be used as backfill materials for sewage pipes, which could ensure higher stability compared with soil backfill.

In the past, the disposal cost of stone sludge in Taiwan was relatively low, and the related reuse or volume reduction technology has not received much attention from the industry. However, due to the lack of natural resources and the increasing difficulty of finding waste disposal sites, stone sludge should be prioritized for resource utilization. On the other hand, the composition of stone sludge and stone waste is not significantly different from the parent stone processed [31], and its output is huge, representing a large resource that can be recycled and reused with great resource potential and economic value. If stone sludge replaces the fine particles in CLSM as an alternative material source, the cost of raw materials can be reduced. In addition, replacing ordinary aggregates with lightweight aggregates can produce low-density CLSM, which can reduce the load on the underground structure and the soil or filler below it.

In view of the above, the development of low-density CLSM by using stone sludge and lightweight aggregates was explored in this study. First, the investigation was performed on a laboratory scale to assess the effects of the composition on the properties of the resulting low-density CLSM. The Taguchi method with an $L_{9}\left(3^{4}\right)$ orthogonal array and four controllable three-level factors (i.e., stone sludge, water/binder ratio, accelerating agent and lightweight aggregate content) was adopted. Then, in order to optimize the selected parameters, the analysis of variance method was used to explore the effects of the experimental factors on the performances (fresh and hardened properties) of the produced low-density CLSM. This study confirmed that the use of stone sludge and lightweight aggregates to produce low-density CLSM was extremely feasible. Especially, in view of the various engineering requirements of CLSM, the Taguchi method could be used to optimize the process parameters of using size stone sludge and lightweight aggregates to produce controlled low-strength materials. 


\section{Materials and Methods}

\subsection{Materials}

A large amount of stone sludge in Taiwan has created an environmental burden. Therefore, this study uses stone sludge in the production of CLSM, and its purpose is to treat stone sludge through recycling and reuse to avoid secondary pollution. The materials used in this study included cement, ground-granulated blast-furnace slag, water, ordinary fine aggregates, lightweight aggregates, stone sludge, accelerating agent and air-entraining agent. The cement used was Type I Portland cement with a specific gravity of 3.15 produced by Taiwan Cement Corporation. The ground-granulated blast-furnace slag was produced by $\mathrm{CHC}$ Resources Corporation and its specific gravity was 2.9. Ordinary fine aggregates were taken from the nearby sand and gravel plant, with a specific gravity of 2.6 and a water absorption rate of $1.1 \%$. Lightweight aggregates were purchased from Ming Chun Ceramic Corporation, and their specific gravity was 1.6. Two kinds of stone sludge were taken from Stone and Resource Industry Research and Development Center in eastern Taiwan, and their chemical composition is shown in Table 1. These stone sludge is characterized by a very fine size distribution, which is mainly made up of the same compounds as the processed stones. Since the particle size of marble stone sludge was larger than that of granite stone sludge, its particle size distribution is shown in Figure 1. Therefore, this study used marble stone sludge with a specific gravity of 2.6 to replace part of the ordinary fine aggregates. The accelerating agent and air-entraining agent were purchased from Guanghui Building Materials Company, in line with the Chinese national standards or the American Society for Testing and Materials specifications, and their specific gravity was 1.05 .

Table 1. The composition of the stone sludge initially examined for research purpose.

\begin{tabular}{|c|c|c|c|}
\hline \multicolumn{2}{|c|}{ Marble Stone Sludge } & \multicolumn{2}{|c|}{ Granite Stone Sludge } \\
\hline Chemical Composition & $(\%)$ & Chemical Composition & $(\%)$ \\
\hline $\mathrm{SiO}_{2}$ & 5.47 & $\mathrm{SiO}_{2}$ & 65.31 \\
\hline $\mathrm{Al}_{2} \mathrm{O}_{3}$ & 1.22 & $\mathrm{Al}_{2} \mathrm{O}_{3}$ & 11.86 \\
\hline $\mathrm{Fe}_{2} \mathrm{O}_{3}$ & 1.10 & $\mathrm{Fe}_{2} \mathrm{O}_{3}$ & 4.23 \\
\hline $\mathrm{Na}_{2} \mathrm{O}$ & 0.18 & $\mathrm{Na}_{2} \mathrm{O}$ & 3.53 \\
\hline $\mathrm{CaO}$ & 46.62 & $\mathrm{CaO}$ & 5.55 \\
\hline $\mathrm{K}_{2} \mathrm{O}$ & 0.33 & $\mathrm{~K}_{2} \mathrm{O}$ & 5.32 \\
\hline $\mathrm{P}_{2} \mathrm{O}_{5}$ & 0.02 & $\mathrm{P}_{2} \mathrm{O}_{5}$ & 0.14 \\
\hline $\mathrm{Cl}$ & ND & $\mathrm{Cl}$ & ND \\
\hline $\mathrm{SO}_{3}$ & 0.09 & $\mathrm{SO}_{3}$ & 0.06 \\
\hline $\mathrm{CuO}$ & 0.01 & $\mathrm{CuO}$ & 0.02 \\
\hline $\mathrm{NiO}$ & 0.01 & $\mathrm{NiO}$ & 0.01 \\
\hline $\mathrm{MnO}$ & 0.02 & $\mathrm{MnO}$ & 0.08 \\
\hline $\mathrm{MgO}$ & 4.35 & $\mathrm{MgO}$ & 1.48 \\
\hline $\mathrm{SrO}$ & 0.04 & $\mathrm{ZnO}$ & 0.01 \\
\hline $\mathrm{TiO}_{2}$ & 0.08 & $\mathrm{SrO}$ & 0.06 \\
\hline $\mathrm{ZrO}_{2}$ & 0.01 & $\mathrm{TiO}_{2}$ & 0.51 \\
\hline $\mathrm{Cr}_{2} \mathrm{O}_{3}$ & 0.02 & $\mathrm{ZrO}_{2}$ & 0.06 \\
\hline- & - & $\mathrm{Cr}_{2} \mathrm{O}_{3}$ & 0.01 \\
\hline- & - & $\mathrm{Rb}_{2} \mathrm{O}$ & 0.02 \\
\hline Loss on Ignition & 40.43 & Loss on Ignition & 1.74 \\
\hline Sum & 100.00 & Sum & 100.00 \\
\hline
\end{tabular}




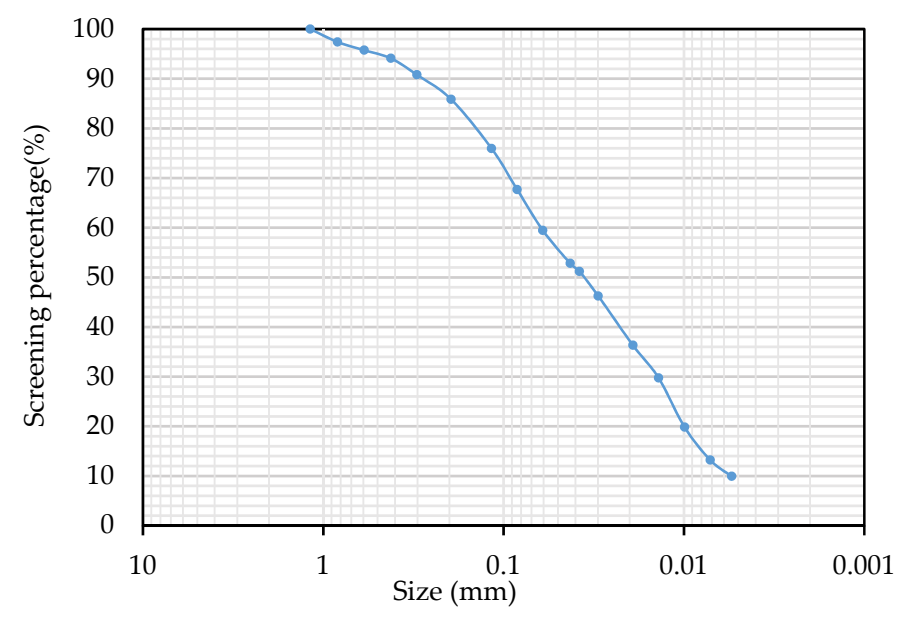

Figure 1. Grain size distribution of the used marble stone sludge.

\subsection{Experimental Design}

This study aimed to produce low-density CLSM using stone sludge and lightweight aggregates. The main component of stone sludge was suspended solids in the raw water-that is, fine sand particles with a specific gravity between 2.6 and 2.8. Because the particle size of stone sludge was relatively fine, this study used it as a filler to replace part of the fine aggregates.

Depending on the application field, such as backfill, utility bedding, void fill, and bridge approach, the important characteristics a CLSM must have are different. The mix proportions of the ingredients in a CLSM mixture depends on the required properties of the CLSM in two states, namely the plastic state and the hardened state. Basically, a CLSM mixture is made by mixing cementitious materials, aggregates, and water in a designed ratio. If necessary, chemical admixtures or mineral admixtures can be used to ensure that the CLSM meets the requirements of fluidity, setting time, and low strength. According to the setting time of CLSM, its mix design is divided into early-strength type and general type. The early-strength CLSM is developed for pipeline projects in urban areas and traffic hubs. It can solve urban construction troubles and keep traffic flow; in addition, it can effectively ensure project quality and construction safety. For conventional CLSM, it is developed for projects that do not require early-strength, non-emergency, and more cost considerations. It is more suitable for pipeline projects in suburbs and industrial areas. Compared with traditional backfilling methods, it can not only improve the quality and safety of general backfilling projects, but also is very economical.

The use of different types and sources of renewable resources is the most important factor that affects the water demand of CLSM. In addition, the water-cement ratio and the type of renewable resources are variables that affect the compressive strength of CLSM. Because CLSM contains a large number of materials that exceed traditional specifications, there is currently no unanimously accepted mix design method. Therefore, based on previous experience and trial and error, we screened out four test variables that needed to be investigated; namely, the percentage of the stone sludge to replace the fine aggregates, the water-binder ratio, the percentage of the accelerating agent and the dosage of the lightweight aggregates. After the experimental control factors were selected, the level of each factor was set to keep the level value within a reasonable range as far as possible. The evaluation indicators of the test included the initial setting time, final setting time, slump, slump flow, unit weight, air content and compressive strength of the CLSM produced.

The main performance characteristics of CLSM include high fluidity and a controllable low strength, and the characteristics of the constituent materials and their proportion in the mixture are the main parameters that affect the performance of CLSM. So far, there is no standard method for CLSM ratio design. The different control levels of each control factor are shown in Table 2 to explore the performance of each control factor level combination 
on the characteristics of CLSM and evaluate the best treatment. The literature showed that renewable resources with fine particle size could be used to replace fine aggregates, and the replacement percentage was usually between $0-90 \%[14,17,21]$. Due to the high-water absorption characteristics of stone sludge, this study believes that the percentage of stone sludge to replace fine aggregates should not be too high. Under the condition of a fixed amount of sand (1450 kg per cubic meter), we planned a total of three stone sludge dosages, and the weight percentages of the stone sludge to replace the fine aggregates were $0 \%, 30 \%$ and $60 \%$. Of these, the proportion of $0 \%$ was the control group, and the other proportions made up the experimental group. In addition, for economic cost considerations, the amount of cement was fixed at $125 \mathrm{~kg}$ per cubic meter, the amount of ground-granulated blastfurnace slag was fixed at $50 \mathrm{~kg}$ per cubic meter, the amount of accelerating agent was between $2 \%$ to $4 \%$ of the binder content and the amount of air-entraining agent was fixed at $1 \%$ of the binder content. It is worth mentioning that the use of accelerating agent was to enhance the early strength of CLSM. However, among various raw materials, the unit price of accelerating agent and air-entraining agent was relatively expensive, so their usage was less.

Table 2. Factors and design levels for test mixtures.

\begin{tabular}{cccccc}
\hline \multirow{2}{*}{ Experimental Control Factor } & \multicolumn{3}{c}{ Levels of Factor } & \multirow{2}{*}{ Performance Parameter } \\
\cline { 2 - 4 } & $\mathbf{1}$ & $\mathbf{2}$ & $\mathbf{3}$ & \\
\hline Stone sludge dosage, A (\%) & 0 & 30 & 60 & Initial setting time, final \\
Water-binder ratio, B & 0.9 & 1.0 & 1.1 & setting time, slump, slump \\
Accelerator dosage, C $(\%)$ & 2 & 3 & 4 & flow, unit weight, air content, \\
aightweight aggregate dosage, $\mathrm{D}\left(\mathrm{kg} / \mathrm{m}^{3}\right)$ & 250 & 300 & 350 & and compressive strength. \\
\hline
\end{tabular}

Under the condition of four factors and three levels for each factor, if the full factor experiment was carried out, the scale of the experiment would be very large (with $3^{4}$ experimental combinations). In this study, an experimental orthogonal array $L_{9}\left(3^{4}\right)$ was selected to arrange the test plan, as shown in Table 3. Then, through the use of range analysis and analysis of variance, it was possible to quickly analyze the effect factors that had a significant impact on the experimental characteristic indexes among many factors to determine the factor combination that could obtain the best characteristic indexes.

Table 3. Orthogonal array $\left(L_{9}\left(3^{4}\right)\right)$ for test mixtures.

\begin{tabular}{ccccc}
\hline \multirow{2}{*}{$\begin{array}{c}\text { Mix } \\
\text { Number }\end{array}$} & \multicolumn{4}{c}{ Factor (Level) } \\
\cline { 2 - 5 } & Sludge Content (\%) & Water-Binder Ratio & AA Content (\%) & LWA Content (\%) \\
\hline M1 & $0(1)^{*}$ & $0.9(1)$ & $2(1)$ & $250(1)$ \\
M2 & $0(1)$ & $1.0(2)$ & $3(2)$ & $300(2)$ \\
M3 & $0(1)$ & $1.1(3)$ & $4(3)$ & $350(3)$ \\
M4 & $30(2)$ & $0.9(1)$ & $3(2)$ & $350(3)$ \\
M5 & $30(2)$ & $1.0(2)$ & $4(3)$ & $250(1)$ \\
M6 & $30(2)$ & $1.1(3)$ & $2(1)$ & $300(2)$ \\
M7 & $60(3)$ & $0.9(1)$ & $4(3)$ & $300(2)$ \\
M8 & $60(3)$ & $1.0(2)$ & $2(1)$ & $350(3)$ \\
M9 & $60(3)$ & $1.1(3)$ & $3(2)$ & $250(1)$ \\
\hline Notes: * The numbers in parentheses indicate the level of the factor. AA = accelerating agent; LWA = lightweight \\
aggregate.
\end{tabular}

\subsection{Mix Proportions Design}

According to the experimental combination of CLSM in the orthogonal design table, the amount of each constituent material was calculated as shown in Table 4. According to the design of the aforementioned various combinations, a horizontal twin-shaft mixer was used to mix CLSM. After the mixing of each group of CLSM was completed, the fresh properties (slump, slump flow, setting time, unit weight and air content) were measured 
and recorded; after that, ninety-one cylindrical test body $(100 \mathrm{~mm}$ in diameter and $200 \mathrm{~mm}$ in height) was cast. The specimens were disassembled according to the planned age and then placed in a water bath for curing. They were not taken out until the day before the test age for the compressive strength test.

Table 4. Mix proportions of test mixtures.

\begin{tabular}{|c|c|c|c|c|c|c|c|c|}
\hline Mix Number & $\begin{array}{l}\text { Cement } \\
\left(\mathrm{kg} / \mathrm{m}^{3}\right)\end{array}$ & $\begin{array}{c}\text { Slag } \\
\left(\mathrm{kg} / \mathrm{m}^{3}\right)\end{array}$ & $\begin{array}{c}\text { Water } \\
\left(\mathrm{kg} / \mathrm{m}^{3}\right)\end{array}$ & $\begin{array}{c}\text { LWA } \\
\left(\mathrm{kg} / \mathrm{m}^{3}\right)\end{array}$ & $\begin{array}{l}\text { Sludge } \\
\left(\mathrm{kg} / \mathrm{m}^{3}\right)\end{array}$ & $\begin{array}{c}\text { FA } \\
\left(\mathrm{kg} / \mathrm{m}^{3}\right)\end{array}$ & $\underset{\left(\mathrm{kg} / \mathrm{m}^{3}\right)}{\mathrm{AA}}$ & $\begin{array}{c}\mathrm{AE} \\
\left(\mathrm{kg} / \mathrm{m}^{3}\right)\end{array}$ \\
\hline M1 & 133.90 & 53.60 & 168.70 & 267.80 & 0.00 & 1553.50 & 1.88 & 3.75 \\
\hline M2 & 127.10 & 50.80 & 177.90 & 304.90 & 0.00 & 1473.90 & 1.78 & 5.34 \\
\hline M3 & 120.90 & 48.30 & 186.10 & 338.40 & 0.00 & 1402.10 & 1.69 & 6.77 \\
\hline M4 & 125.30 & 50.10 & 157.90 & 350.90 & 436.10 & 1017.50 & 1.75 & 5.26 \\
\hline M5 & 131.00 & 52.40 & 183.40 & 262.00 & 455.90 & 1063.70 & 1.83 & 7.34 \\
\hline M6 & 125.00 & 50.00 & 192.60 & 300.10 & 435.20 & 1015.40 & 1.75 & 3.50 \\
\hline M7 & 129.10 & 51.70 & 162.70 & 309.90 & 898.80 & 599.20 & 1.81 & 7.23 \\
\hline M8 & 123.40 & 49.30 & 172.70 & 345.40 & 858.50 & 572.30 & 1.73 & 3.45 \\
\hline M9 & 128.90 & 51.50 & 198.40 & 257.70 & 896.90 & 597.90 & 1.80 & 5.41 \\
\hline
\end{tabular}

Notes: LWA = lightweight aggregate; FA = fine aggregate; $\mathrm{AA}$ = accelerating agent; $\mathrm{AE}$ = air-entraining agent.

\subsection{Test Methods and Data Analysis}

All the mixtures were evaluated in terms of their initial setting time, final setting time, slump, slump flow, unit weight, air content and compressive strength. The slump of the mixture was measured using Chinese National Standard (CNS) 1176 [32], while the slump flow of the mixture was measured using CNS 14842 [33]. The time of setting the mixture was measured using American Society for Testing and Materials (ASTM) C403/C403M16 [34]. The unit weight and air content of the fresh mixture were measured using ASTM D 6023 [35]. The compressive strengths of the hardened mixture were measured at curing ages of 12 h, 24 h, and 28 days, respectively. Three specimens from each mixture were tested for compressive strength. Only one specimen was taken for other test items. The preparation and testing of the mixture specimens were in accordance with CNS 1232 [36].

In the process of discussing optimization, the most important factor is to find the objective function that can best express the quality characteristics. For example, maintaining the overall average value of the product close to the set value or reducing the variation between products can be used as an objective function to improve quality. During the product life cycle, the total price paid by the entire society is called quality loss. The less the quality loss, the higher the quality. In Taguchi's quality concept, parameter design is the most important step to achieve high-quality and low-cost goals. Taguchi believes that the quality characteristics should be concentrated around the target value, and the further away from the target value, the greater the loss. Dr. Taguchi used the loss function of the quadratic curve to measure quality characteristics [37]. When the quality characteristic completely met the target value, the quality loss was zero. When the quality characteristic deviated from the target value, the quality loss increased at the speed of a quadratic curve. The quality loss function $(L)$ is a second-order function, which is defined as: "The quality loss is equal to the square of the difference between the actual value and the target value, multiplied by a quality loss coefficient." It is a criterion for evaluating the quality of a product. Its mathematical function can be expressed as follows [37]:

$$
L(y)=k(y-m)^{2}
$$

where $L=$ quality loss function; $y=$ quality characteristic; $m=$ target value; $k=$ quality loss coefficient. The total quality loss can be calculated as follows:

$$
\text { Total quality loss }=\sum_{i=1}^{n} k\left(y_{i}-m\right)^{2}
$$


where $y_{\mathrm{i}}=$ test value; $n=$ measurement or observation times; $m=$ target value.

There are three standard types of calculation loss function: smaller-the-better, largerthe-better, and nominal-the-better. The signal-to-noise ratio $(S / N)$ is an important evaluation index in Taguchi's quality engineering approach. According to different quality characteristics, the calculation of the $S / N$ ratio $(\eta)$ can be divided into three types [37,38]:

$$
\begin{gathered}
\text { Smaller }- \text { the }- \text { better : } \eta=-10 \times \log \left(\frac{1}{n} \sum_{i=1}^{n} y_{i}^{2}\right) \\
\text { Larger }- \text { the }- \text { better : } \eta=-10 \times \log \left(\frac{1}{n} \sum_{i=1}^{n} \frac{1}{y_{i}^{2}}\right) \\
\text { Nominal }- \text { the }- \text { better : } \eta=-10 \times \log \left(\frac{1}{n} \sum_{i=1}^{n}\left(y_{i}-y_{0}\right)^{2}\right)
\end{gathered}
$$

where $n$ is the number of repetitions or observations, $y_{i}$ is the observed data, and $y_{0}$ is the nominal value desired.

In this study, the objective functions of the mixture specimens were set separately according to engineering requirements. The objective function of the initial setting time, final setting time and unit weight was a smaller-the-better type, while the objective function of the slump, slump flow, air content and compressive strength was a larger-the-better type. On the other hand, the statistical range analysis method was used to explore the relationship between CLSM properties and various control factors. The range was used to represent the measures of variation in statistical data. The difference between the maximum value and the minimum value was taken, which was the data equal to the maximum value minus the minimum value. The range analysis benefits from a simple calculation and intuitiveness and was simple and easy to understand; thus, it is the most used method for the analysis of orthogonal test results. The range analysis process for the test results included the following steps: calculating the range of each factor, determining the order of importance of the factors, drawing a trend graph of the factors and indicators, and determining the optimal level and the optimal level combination of the test factors.

Moreover, an analysis of variance (ANOVA) was used to detect the optimization of the observed values. This was accomplished by separating the total variation of the $S / N$ ratios into contributions by each of the process parameters and the error [39]. In other words, the total variation can be decomposed into two parts: variation due to changes in various factors, and variation due to experimental errors. The different experimental values measured under exactly the same process conditions are all attributed to "experimental error", or simply "error". Analytically, the total sum of square deviation $\left(S S_{T}\right)$ of the $S / N$ ratio can be calculated as [37]:

$$
S S_{T}=\sum_{i=1}^{n}\left(\eta_{i}-\eta_{m}\right)^{2}
$$

where $n$ is the number of experiments in the orthogonal array; $\eta_{i}$ is the mean $S / N$ ratio for the $i^{\text {th }}$ experiment; and $\eta_{m}$ is the grand mean of the $S / N$ ratio. Then, the sum of squares of the measured parameter $\mathrm{Z}\left(S_{\mathrm{Z}}\right)$ can be calculated as [37]:

$$
S S_{Z}=\sum_{J=1}^{r} \frac{Z_{j}^{2}}{t}-\frac{1}{n}\left(\sum_{i=1}^{n} \eta_{i}\right)^{2}
$$

where $Z$ represents one of the tested parameters; $j$ is the level number of parameter $Z$; $r$ is the number of levels of parameter $Z ; t$ is the number of repetitions of each level of parameter $Z$; and $Z_{j}$ is the sum of the $S / N$ ratio involving parameter $Z$ and level $j$. The sum of squares of the error parameter $\left(S S_{e}\right)$ can be calculated as follows [37]:

$$
S S_{e}=S S_{T}-S S_{F}
$$


where $S S_{F}$ represents the sum of squared deviations due to each parameter.

On the other hand, the application of statistical $F$-test can determine which process parameters have a significant impact on performance characteristics. In order to perform the $F$ test, it is necessary to calculate the average of the squared deviation (variation) due to each process parameter and error term, as shown below [37]:

$$
\begin{aligned}
M S_{Z} & =S S_{Z} / d f_{Z} \\
M S_{e} & =S S_{e} / d f_{e}
\end{aligned}
$$

Among them, $M S_{Z}$ is the average value of the square deviation attributed to the parameter $Z ; d f_{Z}$ is the degree of freedom of the parameter $Z ; M S_{e}$ is the average value of the square deviation due to the error term; and $d f_{e}$ is the degree of freedom of the error term. Then, the $F$ value of the parameter $Z\left(F_{Z}\right)$ can be calculated according to the following formula [37]:

$$
F_{Z}=M S_{Z} / M S_{e}
$$

In an orthogonal array experiment, when the $F$ value of a control factor is large, it means that the control factor is influential (important). The corrected sum of squares (SS $\left.S_{Z}^{*}\right)$ can be calculated as follows [37]

$$
S S_{Z}^{*}=S S_{Z}-M S_{e} \times d f_{Z}
$$

Finally, the percentage contribution of parameter $Z\left(P_{Z}\right)$ can be calculated as follows [37]:

$$
P_{Z}=S S_{Z}^{*} / S S_{T}
$$

$P_{Z}$ can be used as a simple indicator to represent the influence of a factor's change, so it can be used as an indicator of the "importance" of a factor.

\section{Results and Discussion}

\subsection{Fresh Properties of Tested Mixtures}

The fresh properties (slump, slump flow, setting time, air content and unit weight) of mixture specimens are shown in Table 5 . As with ordinary concrete, the fresh properties of CLSM were also affected by its composition. It can be seen from Table 5 that the fresh properties of the prepared CLSM were a function of the amount of stone sludge, the water-binder ratio, the accelerating agent, and the lightweight aggregate. The slump of tested mixtures was between 2.0 and $22.5 \mathrm{~cm}$, as shown in Figure 2. Of these, the slump of the M4 mixture was the smallest, and the slump of the M9 mixture was the largest. On the other hand, the slump flow of tested mixtures was between 20 and $38 \mathrm{~cm}$, as shown in Figure 2. Of these, the slump flow of the M2 and M4 mixtures was the smallest, and the slump flow of the M9 mixture was the largest. Regarding the setting time of tested mixtures, the initial setting time was between 159 and $600 \mathrm{~min}$, and the final setting time was between 396 and $1855 \mathrm{~min}$, as shown in Figure 3. Of these, the initial setting time of the M4 mixture was the shortest, the initial setting time of the M3 mixture was the longest, the final setting time of the M6 mixture was the shortest, and the final setting time of the M3 mixture was the longest. In terms of the air content of tested mixtures, its value was between $2.4 \%$ and $5 \%$. The air content of the M1 and M2 mixtures was the smallest, and the air content of the M5 mixture was the largest, as shown in Figure 4. In terms of the unit weight of tested mixtures, its value was between $1961-2346 \mathrm{~kg} / \mathrm{m}^{3}$. The unit weight of the M3 mixture was the smallest, and the unit weight of the M4 mixture was the largest, as shown in Figure 4. From this point of view, the M1-M3 and M9 mixtures can be seen to produce low-density CLSM. 
Table 5. Fresh properties and the corresponding signal-to-noise ratios of tested mixtures.

\begin{tabular}{|c|c|c|c|c|c|c|c|c|c|c|c|c|}
\hline \multirow{3}{*}{ Mix No. } & \multicolumn{6}{|c|}{ Experimental Results } & \multicolumn{6}{|c|}{ Corresponding $S / N$ Ratio (dB) } \\
\hline & \multicolumn{2}{|c|}{$\begin{array}{c}\text { Setting Time } \\
\text { (min.) }\end{array}$} & \multirow{2}{*}{$\underset{(\mathrm{cm})}{\text { Slump }}$} & \multirow{2}{*}{$\begin{array}{c}\text { Slump } \\
\text { Flow } \\
(\mathrm{cm})\end{array}$} & \multirow{2}{*}{$\underset{\substack{\text { Air } \\
\text { Content } \\
(\%)}}{ }$} & \multirow{2}{*}{$\begin{array}{c}\text { Unit } \\
\text { Weight } \\
\left(\mathrm{kg} / \mathrm{m}^{3}\right)\end{array}$} & \multicolumn{2}{|c|}{ Setting Time } & \multirow{2}{*}{ Slump } & \multirow{2}{*}{$\underset{\text { Flow }}{\text { Slump }}$} & \multirow{2}{*}{$\underset{\text { Air }}{\text { Content }}$} & \multirow{2}{*}{$\begin{array}{c}\text { Unit } \\
\text { Weight }\end{array}$} \\
\hline & $\begin{array}{l}\text { Initial } \\
\text { Setting }\end{array}$ & $\begin{array}{l}\text { Final } \\
\text { Setting }\end{array}$ & & & & & $\begin{array}{l}\text { Initial } \\
\text { Setting }\end{array}$ & $\begin{array}{c}\text { Final } \\
\text { Setting }\end{array}$ & & & & \\
\hline M1 & 520 & 1807 & 6.0 & 21 & 2.4 & 1962.9 & -54.32 & -65.14 & 15.56 & 26.44 & 7.60 & -65.86 \\
\hline M2 & 400 & 1256 & 3.0 & 20 & 2.4 & 2084.3 & -52.04 & -61.98 & 9.54 & 26.02 & 7.60 & -66.38 \\
\hline M3 & 600 & 1855 & 6.5 & 21 & 3.0 & 1961.4 & -55.56 & -65.37 & 16.26 & 26.44 & 9.54 & -65.85 \\
\hline M4 & 183 & 476 & 2.0 & 20 & 4.4 & 2345.7 & -45.25 & -53.55 & 6.02 & 26.02 & 12.87 & -67.41 \\
\hline M5 & 212 & 456 & 3.5 & 21 & 5.0 & 2325.7 & -46.53 & -53.18 & 10.88 & 26.44 & 13.98 & -67.33 \\
\hline M6 & 159 & 396 & 4.0 & 21 & 2.9 & 2338.6 & -44.03 & -51.95 & 12.04 & 26.44 & 9.25 & -67.38 \\
\hline M7 & 326 & 1284 & 8.0 & 23 & 4.5 & 2272.9 & -50.26 & -62.17 & 18.06 & 27.23 & 13.06 & -67.13 \\
\hline M8 & 409 & 1295 & 18.5 & 32 & 3.1 & 2210.0 & -52.23 & -62.25 & 25.34 & 30.10 & 9.83 & -66.89 \\
\hline M9 & 347 & 1012 & 22.5 & 38 & 3.2 & 2198.6 & -50.81 & -60.10 & 27.04 & 31.60 & 10.10 & -66.84 \\
\hline
\end{tabular}

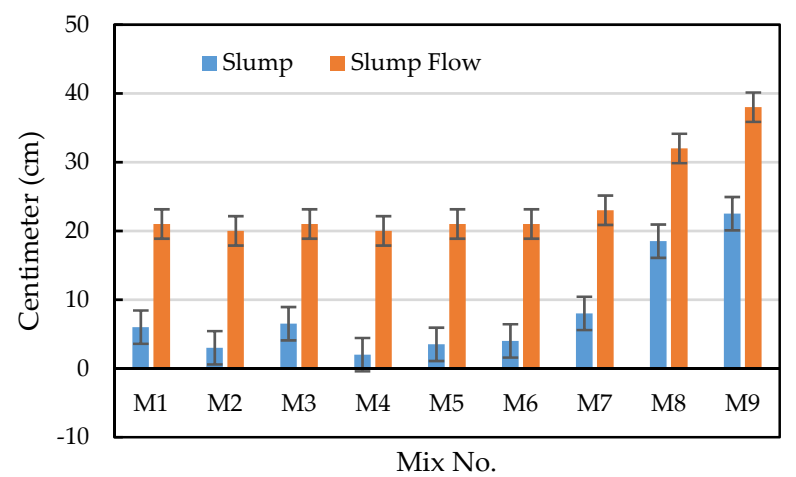

Figure 2. Slump and slump flow test results of tested mixtures.

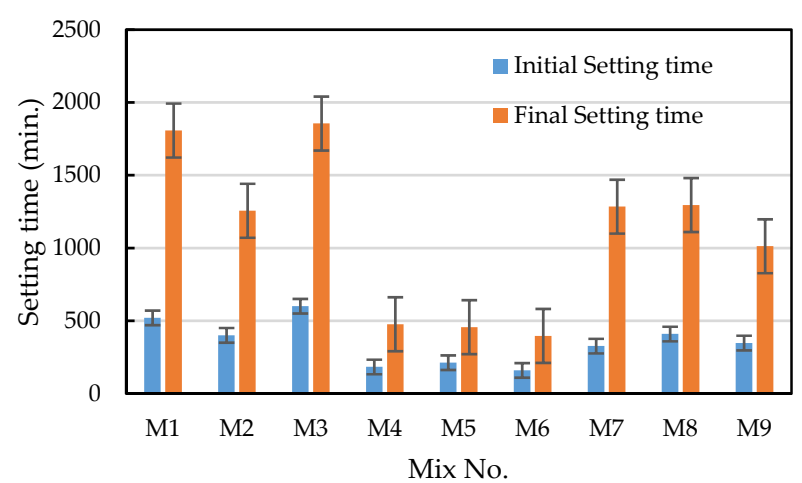

Figure 3. Setting time test results of tested mixtures.

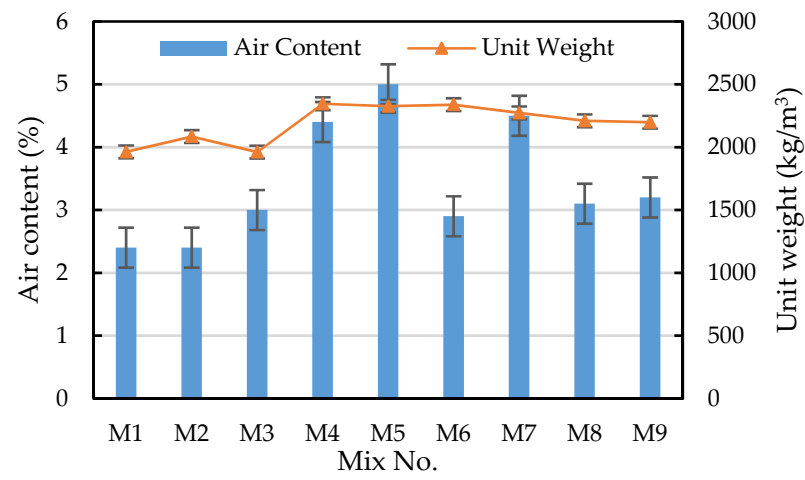

Figure 4. Air content and unit weight test results of tested mixtures.

On the other hand, Kaliyavaradhan et al. [40] pointed out that researchers who used different types of wastes with high water absorption rates as fine aggregate substitutes 
in CLSM often observed negative effects on the fresh properties. For example, the test results showed that when the percentage of stone sludge usage was increased from $30 \%$ to $60 \%$, the initial setting time approximately doubled on average. In other words, the setting time increased with the increase of stone sludge dosage in the CLSM mixture. In order to further understand the appropriateness of the properties of the prepared CLSM specimens, a comparison was made with the test results of other researchers. Although different researchers used different composition materials, the test results were still available for reference, as shown in Table 6 . On the whole, the results of the fresh properties of this study were included in the scope of the existing literature. Taking the slump flow as an example, the results of this study ranged from 20 to $38 \mathrm{~cm}$, while the literature range was 0 to $65 \mathrm{~cm}$. This means that the various properties of the produced CLSM were within a reasonable range. From this point of view, it is feasible to produce CLSM from stone sludge.

Table 6. Comparison of test results and literature.

\begin{tabular}{|c|c|c|c|c|c|c|c|c|c|}
\hline \multirow{2}{*}{ Literature } & \multirow{2}{*}{$\begin{array}{l}\text { Initial } \\
\text { Setting }\end{array}$} & \multirow{2}{*}{$\begin{array}{l}\text { Final } \\
\text { Setting }\end{array}$} & \multirow{2}{*}{ Slump } & \multirow{2}{*}{$\underset{(\mathrm{cm})}{\text { Slump Flow }}$} & \multirow{2}{*}{$\underset{(\%)}{\text { Air Content }}$} & \multirow{2}{*}{$\begin{array}{l}\text { Unit Weight } \\
\left(\mathrm{kg} / \mathrm{m}^{3}\right)\end{array}$} & \multicolumn{3}{|c|}{ Compressive Strength } \\
\hline & & & & & & & $12 \mathrm{~h}$ & One Day & 28 Days \\
\hline This research & $159-600$ & $396-1855$ & $2-22.5$ & $20-38$ & $2.4-5.0$ & $1961.4-2345.7$ & $0.02-0.62$ & $0.20-1.49$ & $1.37-9.86$ \\
\hline Lachemi et al. [17] & - & - & - & $0-53.5$ & $1.2-2.8$ & $1787-2028$ & - & - & $0.7-4.0$ \\
\hline Shon et al. [18] & $300-660$ & - & - & $21.1-25.5$ & - & - & - & - & $0.70-0.95$ \\
\hline Lin et al. [19] & - & - & - & $41.9-54.9$ & - & - & - & - & $4.0-8.5$ \\
\hline Kuo \& Gao [20] & - & - & $26.5-26.8$ & $56.9-65.3$ & - & - & - & - & $5.87-6.25$ \\
\hline Kuo et al. [24] & - & - & $21.5-26.5$ & $41-60$ & - & - & - & $0.96-1.67$ & $4.21-6.63$ \\
\hline Fang et al. [27] & - & $210-270$ & - & $21-23$ & - & - & - & - & $1.18-1.58$ \\
\hline Hung et al. [29] & - & - & - & - & - & - & - & $0.2-1.3$ & $2.7-7.2$ \\
\hline Park \& Hong [30] & - & - & - & - & - & - & - & $0.04-1.4$ & $0.53-5.84$ \\
\hline Trejo et al. [41] & - & - & - & $13-25$ & $0.5-28.5$ & $1382-2291$ & - & - & - \\
\hline Do \& Kim [42] & $386-586$ & - & - & $24-30$ & - & & - & - & $0.5-0.85$ \\
\hline Razak et al. [43] & $360-1608$ & - & - & - & - & $1528-1560$ & - & - & $0.12-1.73$ \\
\hline Türkel [44] & - & - & - & $20.5-22$ & - & $1944-2064$ & - & - & $0.85-1.15$ \\
\hline Taha et al. [45] & - & - & $22-25$ & - & - & $1380-2140$ & - & - & $0.084-0.85$ \\
\hline
\end{tabular}

In order to analyze the effect of each factor, we calculated the average value of the $S / N$ ratio of each factor at the same level, and then calculated the main effect value (delta) of the factor level. In this way, these data could be made into an auxiliary table as shown in Table 7. If the main effect value of one of the factors was larger, it meant that the influence of the factor on the whole system was greater, and the quality of improvement was also greater. It can be seen from Table 7 that the influence of $\mathrm{A}_{1}$ (i.e., the level of $\mathrm{A}$ factor was under the condition of the first level) was reflected in the experimental combination of $\mathrm{M} 1-\mathrm{M} 3$, the influence of $\mathrm{A}_{2}$ was reflected in the experimental combination of M4-M6, and the influence of $A_{3}$ was reflected in the experimental combination of M7-M9. In Table 7, delta represents the calculated range; that is, the difference between the maximum value and the minimum value in levels 1-3. In the same way, the influence of the water-binder ratio, the accelerator dosage and the lightweight aggregate dosage on the performance parameters can be analyzed. In principle, the greater the delta value, the greater the influence of the level change of the factor on the performance parameters; that is, the more important the factor. On the other hand, a statistical method, ANOVA, was used to further explore the test results. The results of the ANOVA for the fresh properties of tested mixtures are shown in Table 8. The total variation represents the possible total quality loss. In addition, the $F$ value and $P$ value obtained under a confidence level of $95 \%$ and the contribution percentage of each parameter are also listed in the table, which represents the proportion of the variation of the factor to the total quality loss. 
Table 7. Range analysis for fresh properties of tested mixtures.

\begin{tabular}{|c|c|c|c|c|c|c|}
\hline \multirow{2}{*}{$\begin{array}{l}\text { Performance } \\
\text { Parameter }\end{array}$} & \multirow{2}{*}{ Experimental Control Factor } & \multicolumn{3}{|c|}{ Mean $S / N$ Ratio ( $\eta$, Unit: dB) } & \multirow{2}{*}{$\begin{array}{c}\text { Delta } \\
(\text { Max. } \eta-\text { Min. } \eta)\end{array}$} & \multirow[b]{2}{*}{ Rank } \\
\hline & & Level 1 & Level 2 & Level 3 & & \\
\hline \multirow{4}{*}{ Initial setting time } & Stone sludge dosage, A (\%) & -53.97 & -45.27 & -51.10 & 8.707 & 1 \\
\hline & Water-binder ratio, B & -49.94 & -50.27 & -50.13 & 0.323 & 4 \\
\hline & Accelerator dosage, C (\%) & -50.19 & -49.37 & -50.78 & 1.419 & 3 \\
\hline & LWA dosage, $\mathrm{D}\left(\mathrm{kg} / \mathrm{m}^{3}\right)$ & -50.55 & -48.78 & -51.02 & 2.238 & 2 \\
\hline \multirow{4}{*}{ Final setting time } & Stone sludge dosage, A (\%) & -64.16 & -52.90 & -61.51 & 11.267 & 1 \\
\hline & Water-binder ratio, B & -60.29 & -59.13 & -59.14 & 1.153 & 4 \\
\hline & Accelerator dosage, C (\%) & -59.78 & -58.55 & -60.24 & 1.694 & 2 \\
\hline & LWA dosage, $\mathrm{D}\left(\mathrm{kg} / \mathrm{m}^{3}\right)$ & -59.47 & -58.70 & -60.39 & 1.686 & 3 \\
\hline \multirow{4}{*}{ Slump } & Stone sludge dosage, A (\%) & 13.79 & 9.65 & 23.48 & 13.835 & 1 \\
\hline & Water-binder ratio, B & 13.22 & 15.26 & 18.45 & 5.233 & 2 \\
\hline & Accelerator dosage, C (\%) & 17.65 & 14.20 & 15.07 & 3.447 & 4 \\
\hline & LWA dosage, $\mathrm{D}\left(\mathrm{kg} / \mathrm{m}^{3}\right)$ & 17.83 & 13.22 & 15.87 & 4.614 & 3 \\
\hline \multirow{4}{*}{ Slump flow } & Stone sludge dosage, A (\%) & 26.30 & 26.30 & 29.64 & 3.341 & 1 \\
\hline & Water-binder ratio, B & 26.57 & 27.52 & 28.16 & 1.595 & 2 \\
\hline & Accelerator dosage, C (\%) & 27.66 & 27.88 & 26.71 & 1.171 & 4 \\
\hline & LWA dosage, $\mathrm{D}\left(\mathrm{kg} / \mathrm{m}^{3}\right)$ & 28.16 & 26.57 & 27.52 & 1.595 & 3 \\
\hline \multirow{4}{*}{ Air content } & Stone sludge dosage, A (\%) & 8.25 & 12.03 & 11.00 & 3.782 & 1 \\
\hline & Water-binder ratio, $\mathrm{B}$ & 11.18 & 10.47 & 9.63 & 1.548 & 3 \\
\hline & Accelerator dosage, C (\%) & 8.89 & 10.19 & 12.20 & 3.302 & 2 \\
\hline & LWA dosage, $\mathrm{D}\left(\mathrm{kg} / \mathrm{m}^{3}\right)$ & 10.56 & 9.97 & 10.75 & 0.774 & 4 \\
\hline \multirow{4}{*}{ Unit weight } & Stone sludge dosage, A (\%) & -66.03 & -67.37 & -66.95 & 1.342 & 1 \\
\hline & Water-binder ratio, B & -66.80 & -66.87 & -66.69 & 0.175 & 3 \\
\hline & Accelerator dosage, C (\%) & -66.71 & -66.88 & -66.77 & 0.168 & 4 \\
\hline & LWA dosage, $\mathrm{D}\left(\mathrm{kg} / \mathrm{m}^{3}\right)$ & -66.68 & -66.96 & -66.71 & 0.286 & 2 \\
\hline
\end{tabular}

Note: $S / N=$ signal-to-noise ratio; $L W A=$ lightweight aggregate.

Table 8. Analysis of variance and $F$ test for fresh properties of tested mixtures.

\begin{tabular}{|c|c|c|c|c|c|c|}
\hline $\begin{array}{c}\text { Performance } \\
\text { Parameter }\end{array}$ & Experimental Control Factor & $\begin{array}{c}\text { Sum of Square } \\
\left(S S_{Z}\right)\end{array}$ & $\begin{array}{l}\text { Degree of } \\
\text { Freedom }\end{array}$ & $\begin{array}{c}\text { Variation } \\
\left(M S_{Z}\right)\end{array}$ & $\begin{array}{c}F \text { Value } \\
\left(F_{Z}\right)\end{array}$ & $\begin{array}{c}\text { Percentage } \\
\text { Contribution }\left(P_{Z}\right)\end{array}$ \\
\hline \multirow{6}{*}{$\begin{array}{c}\text { Initial } \\
\text { setting time }\end{array}$} & Stone sludge dosage, A (\%) & 118.10 & 3 & 39.37 & 748.00 & 90.95 \\
\hline & Water-binder ratio, $\mathrm{B}$ & 0.16 & 3 & 0.05 & 1.00 & 0.00 \\
\hline & Accelerator dosage, C (\%) & 3.05 & 3 & 1.02 & 19.31 & 2.72 \\
\hline & LWA dosage, $\mathrm{D}\left(\mathrm{kg} / \mathrm{m}^{3}\right)$ & 8.37 & 3 & 2.79 & 53.00 & 6.33 \\
\hline & All others/error & 0.16 & 3 & 0.05 & - & - \\
\hline & Total & 129.67 & 12 & 43.22 & - & 100.00 \\
\hline \multirow{6}{*}{$\begin{array}{l}\text { Final } \\
\text { setting time }\end{array}$} & Stone sludge dosage, A (\%) & 208.15 & 3 & 69.38 & 78.78 & 93.55 \\
\hline & Water-binder ratio, B & 2.64 & 3 & 0.88 & 1.00 & 0.00 \\
\hline & Accelerator dosage, C (\%) & 4.60 & 3 & 1.53 & 1.74 & 5.70 \\
\hline & LWA dosage, $\mathrm{D}\left(\mathrm{kg} / \mathrm{m}^{3}\right)$ & 4.28 & 3 & 1.43 & 1.62 & 0.74 \\
\hline & All others/error & 2.64 & 3 & 0.88 & - & - \\
\hline & Total & 219.68 & 12 & 73.23 & - & 100.00 \\
\hline \multirow{6}{*}{ Slump } & Stone sludge dosage, A (\%) & 302.55 & 3 & 100.85 & 15.68 & 71.57 \\
\hline & Water-binder ratio, B & 41.73 & 3 & 13.91 & 2.16 & 5.67 \\
\hline & Accelerator dosage, C (\%) & 19.30 & 3 & 6.43 & 1.00 & 19.50 \\
\hline & LWA dosage, $\mathrm{D}\left(\mathrm{kg} / \mathrm{m}^{3}\right)$ & 32.18 & 3 & 10.73 & 1.67 & 3.26 \\
\hline & All others/error & 19.30 & 3 & 6.43 & - & - \\
\hline & Total & 395.76 & 12 & 131.92 & - & 100.00 \\
\hline
\end{tabular}


Table 8. Cont.

\begin{tabular}{|c|c|c|c|c|c|c|}
\hline $\begin{array}{c}\text { Performance } \\
\text { Parameter }\end{array}$ & Experimental Control Factor & $\begin{array}{c}\text { Sum of Square } \\
\left(S S_{Z}\right)\end{array}$ & $\begin{array}{l}\text { Degree of } \\
\text { Freedom }\end{array}$ & $\begin{array}{c}\text { Variation } \\
\left(M S_{Z}\right)\end{array}$ & $\begin{array}{c}F \text { Value } \\
\left(F_{Z}\right)\end{array}$ & $\begin{array}{c}\text { Percentage } \\
\text { Contribution }\left(P_{Z}\right)\end{array}$ \\
\hline \multirow{6}{*}{ Slump flow } & Stone sludge dosage, A (\%) & 22.33 & 3 & 7.44 & 9.57 & 61.73 \\
\hline & Water-binder ratio, B & 3.87 & 3 & 1.29 & 1.66 & 4.74 \\
\hline & Accelerator dosage, C (\%) & 2.33 & 3 & 0.78 & 1.00 & 28.80 \\
\hline & LWA dosage, $\mathrm{D}\left(\mathrm{kg} / \mathrm{m}^{3}\right)$ & 3.87 & 3 & 1.29 & 1.66 & 4.74 \\
\hline & All others/error & 2.33 & 3 & 0.78 & - & - \\
\hline & Total & 32.39 & 12 & 10.80 & - & 100.00 \\
\hline \multirow{6}{*}{ Air content } & Stone sludge dosage, A (\%) & 22.92 & 3 & 7.64 & 23.36 & 49.74 \\
\hline & Water-binder ratio, B & 3.60 & 3 & 1.20 & 3.67 & 5.94 \\
\hline & Accelerator dosage, C (\%) & 16.61 & 3 & 5.54 & 16.92 & 44.32 \\
\hline & LWA dosage, $\mathrm{D}\left(\mathrm{kg} / \mathrm{m}^{3}\right)$ & 0.98 & 3 & 0.33 & 1.00 & 0.00 \\
\hline & All others/error & 0.98 & 3 & 0.33 & - & - \\
\hline & Total & 44.11 & 12 & 14.70 & - & 100.00 \\
\hline \multirow{6}{*}{ Unit weight } & Stone sludge dosage, A (\%) & 2.83 & 3 & 0.94 & 65.89 & 90.95 \\
\hline & Water-binder ratio, B & 0.05 & 3 & 0.02 & 1.09 & 0.12 \\
\hline & Accelerator dosage, C (\%) & 0.04 & 3 & 0.01 & 1.00 & 5.61 \\
\hline & LWA dosage, $\mathrm{D}\left(\mathrm{kg} / \mathrm{m}^{3}\right)$ & 0.14 & 3 & 0.05 & 3.37 & 3.33 \\
\hline & All others/error & 0.04 & 3 & 0.01 & - & - \\
\hline & Total & 3.07 & 12 & 1.02 & - & 100.00 \\
\hline
\end{tabular}

Note: LWA = lightweight aggregate.

\subsubsection{Setting Time}

For the setting time of tested mixtures, the objective function was a smaller-the-better type. From the range analysis results in Table 7 , in order to shorten the initial setting time of tested mixtures, the order of importance of the control factors was the stone sludge dosage (factor $\mathrm{A})$, the lightweight aggregate dosage (factor $\mathrm{D})$, the accelerator dosage (C factor) and the water-binder ratio (B factor); the corresponding delta values were 8.707, 2.238, 1.419 and 0.323 , respectively. Moreover, the $S / N$ response graph for the initial setting time of tested mixtures is shown in Figure 5. When the use percentage of stone sludge decreased from $30 \%$ to $0 \%$, the $S / N$ ratio decreased significantly, which reflected a significant increase in the initial setting time. It can be seen from the test results that the initial setting time was increased by approximately 2.7 times on average. In addition, when the percentage of stone sludge usage was increased from $30 \%$ to $60 \%$, the $S / N$ ratio decreased significantly, which reflected a significant increase in the initial setting time. It can be seen from the test results that the initial setting time approximately doubled on average. Therefore, the stone sludge dosage had the greatest impact and was the main factor. On the other hand, from the ANOVA results in Table 8, the most significant factor affecting the initial setting time was the stone sludge dosage, and its contribution percentage $\left(P_{Z}\right)$ was $90.95 \%$. The purpose of the prepared CLSM is to emphasize the need to shorten the initial setting time; that is, the shorter the initial setting time, the better. According to the experimental results, the optimal combination is $\mathrm{A}_{2} \mathrm{~B}_{3} \mathrm{C}_{1} \mathrm{D}_{2}$, and the shortest initial setting time was $159 \mathrm{~min}$. However, the best combination estimated by the range analysis and ANOVA was $\mathrm{A}_{2} \mathrm{~B}_{1} \mathrm{C}_{2} \mathrm{D}_{2}$, i.e., stone sludge dosage at level 2, water-binder ratio at level 1, accelerator dosage at level 2, and lightweight aggregate dosage at level 2.

In terms of shortening the final setting time of the tested mixtures, the range analysis results in Table 7 show that the order of importance of the control factors was the stone sludge dosage, the accelerator dosage the accelerator dosage, the lightweight aggregate dosage, and the water-binder ratio; the corresponding delta values were 11.267, 1.694, 1.686 and 1.153 , respectively. In addition, the $S / N$ response graph for the final setting time of tested mixtures is shown in Figure 6. When the use percentage of stone sludge decreased from $30 \%$ to $0 \%$, the $S / N$ ratio decreased significantly, which reflected a significant increase in the final setting time. It can be seen from the test results that the final setting time was 
increased by approximately 2.7 times on average. In addition, when the percentage of stone sludge usage was increased from $30 \%$ to $60 \%$, the $S / N$ ratio decreased significantly, which reflected a significant increase in final setting time. It can be seen from the test results that the final setting time increased by approximately 2.7 times on average. From this point of view, the stone sludge dosage (factor A) had the greatest impact and was the main factor, while the accelerator dosage was the secondary factor. On the other hand, from the ANOVA results in Table 8, the most significant factor affecting the final setting time was the stone sludge dosage, and its contribution percentage $\left(P_{Z}\right)$ was $93.55 \%$. The purpose of the prepared CLSM is to emphasize the need to shorten the final setting time. That is to say, the shorter the final setting time, the better. According to the experimental results, the optimal combination was $\mathrm{A}_{2} \mathrm{~B}_{3} \mathrm{C}_{1} \mathrm{D}_{2}$, and the shortest final setting time was $396 \mathrm{~min}$. In contrast, the best combination estimated by range analysis and ANOVA was $\mathrm{A}_{2} \mathrm{~B}_{2} \mathrm{C}_{2} \mathrm{D}_{2}$, i.e., stone sludge dosage at level 2, water-binder ratio at level 2, accelerator dosage at level 2 , and lightweight aggregate dosage at level 2.

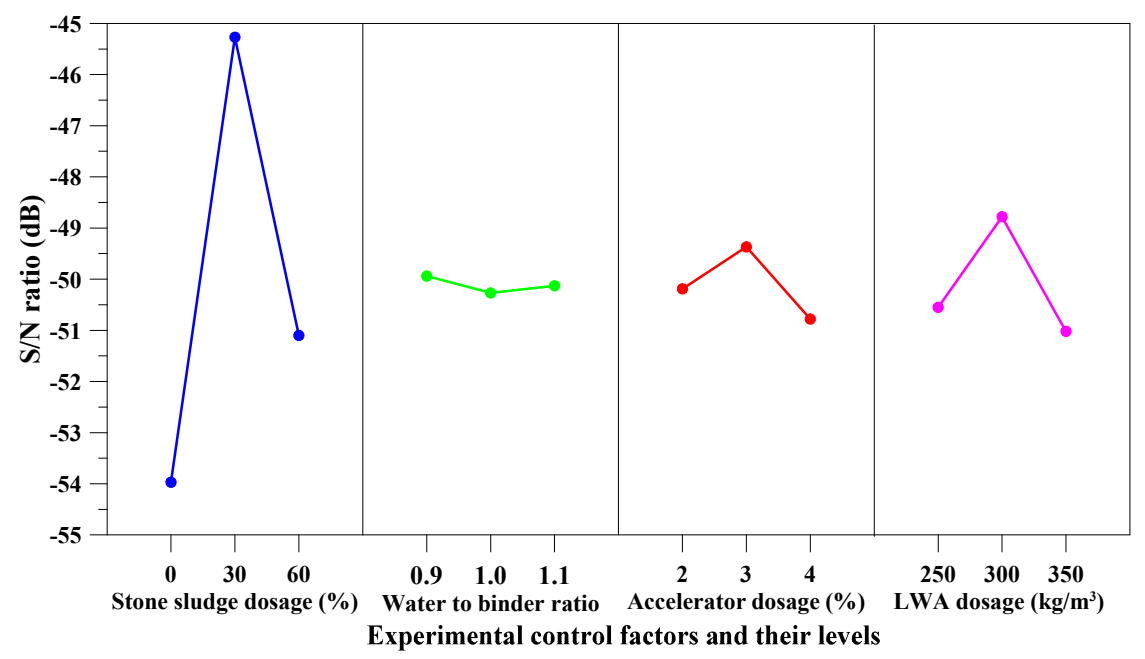

Figure 5. Signal-to-noise $(S / N)$ response graph for the initial setting time of tested mixtures.

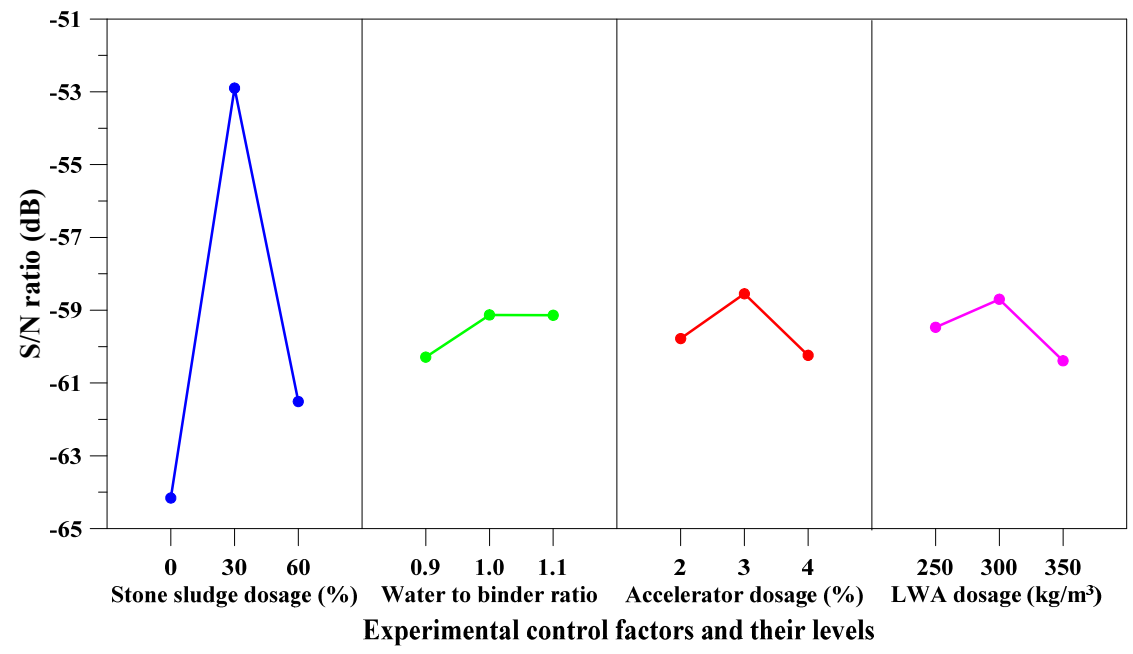

Figure 6. Signal-to-noise $(S / N)$ response graph for final setting time of tested mixtures.

\subsubsection{Slump and Slump Flow}

For the slump and slump flow of tested mixtures, the objective function was a largerthe-better type. From the results of the range analysis in Table 7 when increasing the slump of CLSM, the order of importance of the control factors was the stone sludge dosage (factor A), the water-binder ratio (factor B), the lightweight aggregate dosage (factor D) 
and the accelerator dosage (factor C); the corresponding delta values were 13.835, 5.233, 4.614 and 3.447, respectively. In addition, the $S / N$ response graph for the slump of tested mixtures is shown in Figure 7 . When the use percentage of stone sludge decreased from $30 \%$ to $0 \%$, the $S / N$ ratio increased, which reflected an increase in the slump. It can be seen from the test results that the slump was increased by approximately 1.6 times on average. In addition, When the percentage of stone sludge usage increased from $30 \%$ to $60 \%$, the $S / N$ ratio increased significantly, which reflected a significant increase in the slump. In addition, as the water-binder ratio increased, the $S / N$ ratio increased significantly, which reflected a significant increase in the slump. Therefore, the stone sludge dosage (factor A) had the greatest impact and was the main factor, while the water-binder ratio (factor B) was the secondary factor. Furthermore, from the ANOVA results in Table 8, the most significant factor affecting the slump was the stone sludge dosage, and its contribution percentage $\left(P_{Z}\right)$ was $71.57 \%$. The purpose of the prepared CLSM is to emphasize the need for increasing slump. The larger the slump, the better. According to the experimental results, the optimal combination was $\mathrm{A}_{3} \mathrm{~B}_{2} \mathrm{C}_{2} \mathrm{D}_{1}$, and the maximum slump was $22.5 \mathrm{~cm}$. However, the best combination estimated by range analysis and ANOVA was $A_{3} B_{3} C_{1} D_{1}$, i.e., stone sludge dosage at level 3 , water-binder ratio at level 3 , accelerator dosage at level 1 , and lightweight aggregate dosage at level 1.

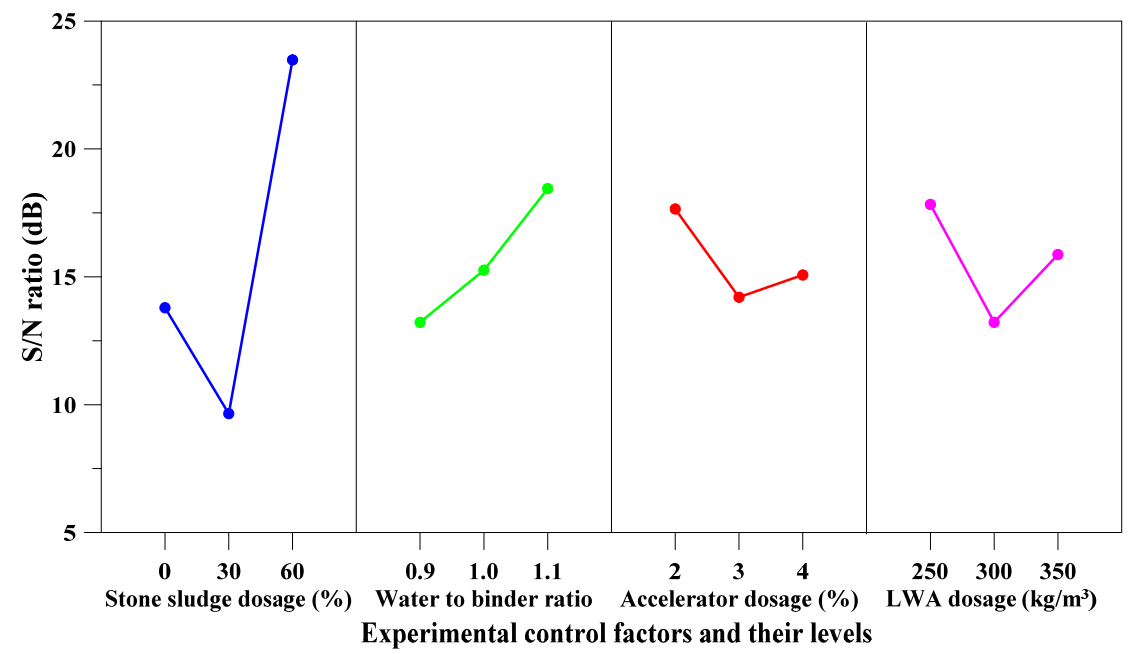

Figure 7. Signal-to-noise $(S / N)$ response graph for slump of tested mixtures.

It can be seen from Table 7 that when increasing the slump flow of tested mixtures, the order of importance of the control factors was the stone sludge dosage (factor A), the water-binder ratio (factor B), the lightweight aggregate dosage (factor D) and the accelerator dosage (factor $\mathrm{C}$ ). Moreover, the $S / N$ response graph for the slump flow of tested mixtures is shown in Figure 8. When the use percentage of stone sludge was reduced from $30 \%$ to $0 \%$, the signal-to-noise ratio did not change, which reflected that there was basically no change in the slump flow. In addition, when the percentage of stone sludge usage increased from $30 \%$ to $60 \%$, the $S / N$ ratio increased significantly, which reflected a significant increase in the slump flow. Moreover, as the water-binder ratio increased, the $S / N$ ratio increased significantly, which reflected a significant increase in the slump flow. Therefore, the stone sludge dosage (factor A) had the greatest impact and was the main factor, while the water-binder ratio (factor B) was the secondary factor. Furthermore, from the ANOVA results in Table 8, the most significant factor affecting the slump was the stone sludge dosage, and its contribution percentage $\left(P_{Z}\right)$ was $71.57 \%$. The purpose of the prepared CLSM is to emphasize the need for increasing slump. The larger the slump, the better. According to the experimental results, the optimal combination was $\mathrm{A}_{3} \mathrm{~B}_{3} \mathrm{C}_{2} \mathrm{D}_{1}$, and the maximum slump flow was $38 \mathrm{~cm}$. Coincidentally, the best combination estimated by range analysis and ANOVA was also $\mathrm{A}_{3} \mathrm{~B}_{3} \mathrm{C}_{2} \mathrm{D}_{1}$. 


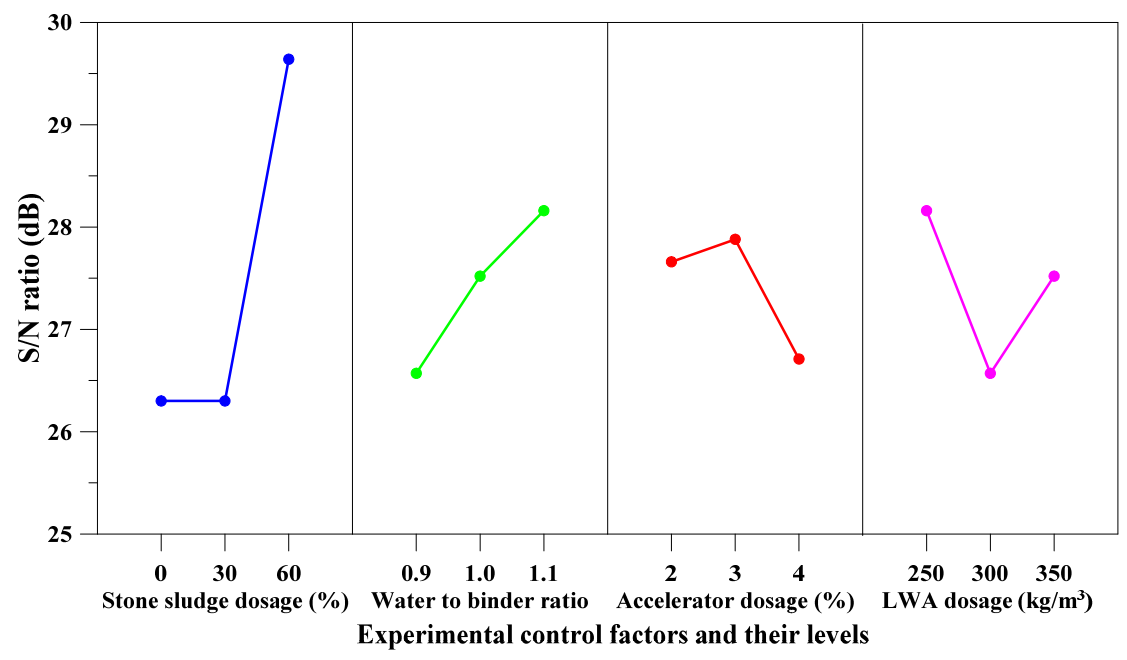

Figure 8. Signal-to-noise $(S / N)$ response graph for slump flow of tested mixtures.

\subsubsection{Air Content and Unit Weight}

For the air content of tested mixtures, the objective function was a larger-the-better type. From the range analysis results in Table 7 , in order to increase the air content of CLSM, the order of importance of the control factors was the stone sludge dosage (factor A), the accelerator dosage (factor C), the water to binder ratio (factor B) and the lightweight aggregate dosage (factor D); the corresponding delta values were 3.782, 3.302, 1.548 and 0.774 , respectively. Moreover, the $S / N$ response graph for the air content of tested mixtures is shown in Figure 9. When the use percentage of stone sludge decreased from $30 \%$ to $0 \%$, the $S / N$ ratio decreased significantly, which reflected a significant decrease in the air content. Moreover, when the percentage of stone sludge usage increased from $30 \%$ to $60 \%$, the $S / N$ ratio decreased significantly, which reflected a significant decrease in the air content. In addition, as the accelerator dosage increased, the $S / N$ ratio increased significantly, which reflected a significant increase in the air content. Therefore, the stone sludge dosage had the greatest impact and was the main factor, while the accelerator dosage was the secondary factor. On the other hand, from the ANOVA results in Table 8, the most significant factor affecting the air content was the stone sludge dosage, and its contribution percentage $\left(P_{Z}\right)$ was $49.74 \%$. The purpose of the prepared CLSM is to emphasize the need to increase the air content; that is, the larger the air content, the better. According to the experimental results, the optimal combination was $\mathrm{A}_{2} \mathrm{~B}_{2} \mathrm{C}_{3} \mathrm{D}_{1}$, and the largest air content was $5 \%$. However, the best combination estimated by range analysis and ANOVA was $A_{2} B_{1} C_{3} D_{3}$, i.e., stone sludge dosage at level 2, water-binder ratio at level 1, accelerator dosage at level 3 , and lightweight aggregate dosage at level 3.

For the unit weight of tested mixtures, the objective function was a smaller-the-better type. From the range analysis results in Table 7 , in order to reduce the unit weight of CLSM, the order of importance of the control factors was the stone sludge dosage (factor A), the lightweight aggregate dosage (factor D), the water-binder ratio (factor B), and the accelerator dosage (factor C); the corresponding delta values were 1.342, 0.286, 0.175 and 0.168 , respectively. Moreover, the $S / N$ response graph for the unit weight of tested mixtures is shown in Figure 10. When the use percentage of stone sludge decreased from $30 \%$ to $0 \%$, the $\mathrm{S} / \mathrm{N}$ ratio increased significantly, which reflected a significant decrease in the unit weight. In addition, when the percentage of stone sludge usage increased from $30 \%$ to $60 \%$, the $\mathrm{S} / \mathrm{N}$ ratio increased significantly, which reflected a significant decrease in the unit weight. Therefore, the stone sludge dosage had the greatest impact and was the main factor, while the lightweight aggregate dosage was the secondary factor. On the other hand, from the ANOVA results in Table 8, the most significant factor affecting the unit weight was the stone sludge dosage, and its contribution percentage $\left(P_{Z}\right)$ was $90.95 \%$. The purpose of the prepared CLSM is to emphasize the need to reduce the unit weight; that 
is, the lighter the unit weight, the better. According to the experimental results, the optimal combination was $A_{1} B_{3} C_{3} D_{3}$, and the lightest unit weight was $1961.4 \mathrm{~kg} / \mathrm{m}^{3}$. However, the best combination estimated by range analysis and ANOVA was $A_{1} B_{3} C_{1} D_{1}$, i.e., stone sludge dosage at level 1 , water-binder ratio at level 3, accelerator dosage at level 1 , and lightweight aggregate dosage at level 1.

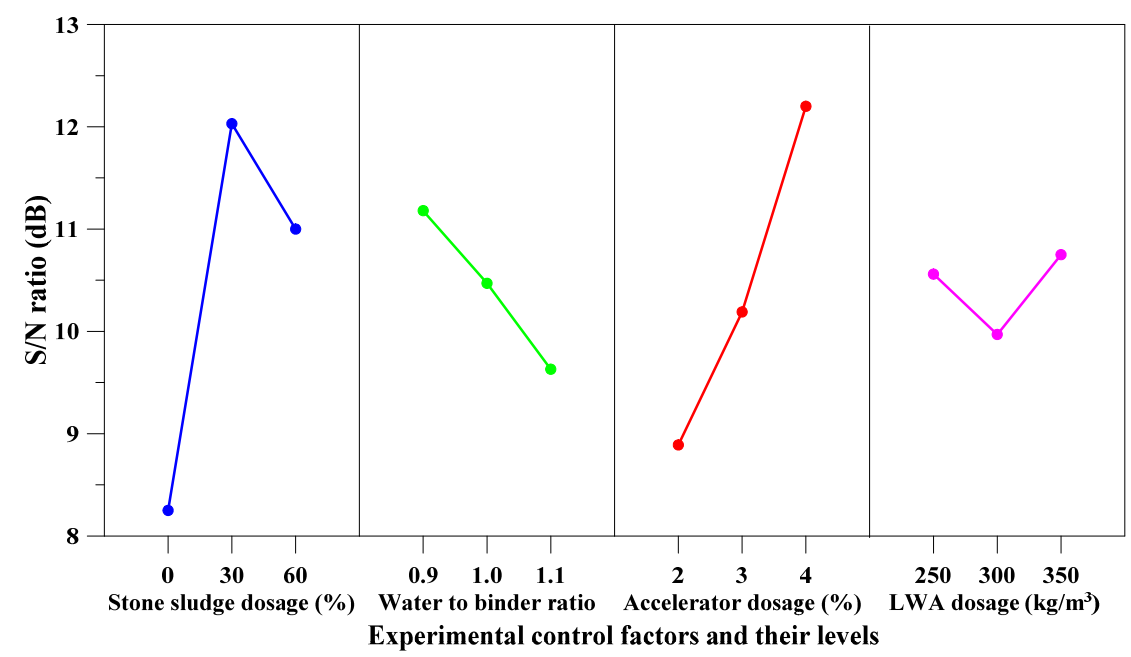

Figure 9. Signal-to-noise $(S / N)$ response graph for air content of tested mixtures.

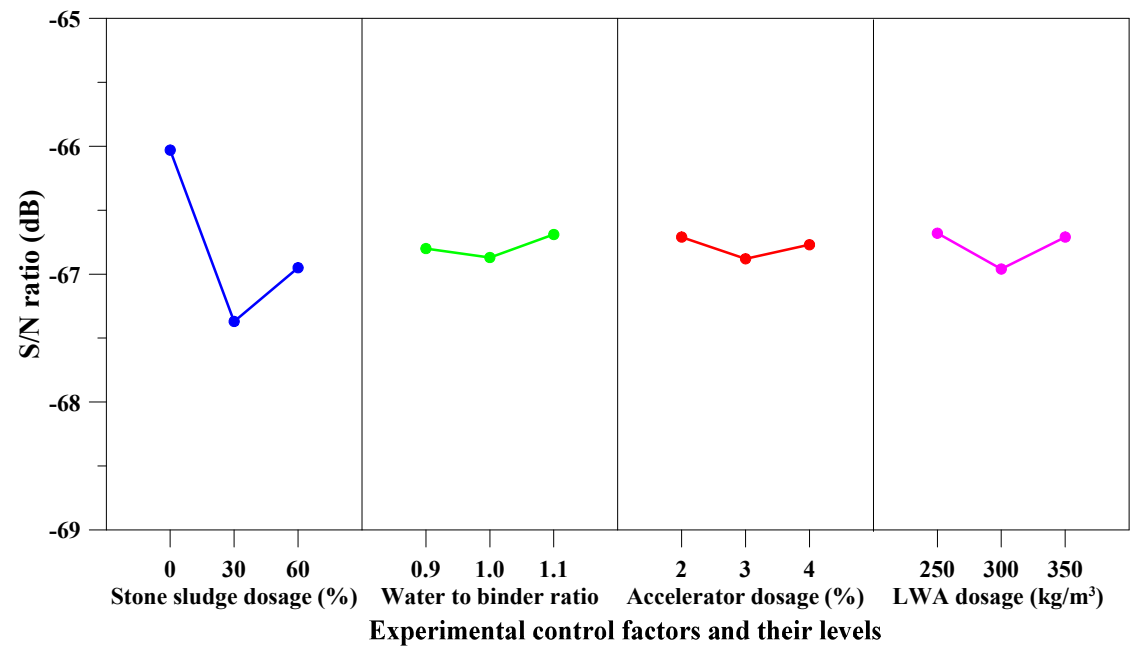

Figure 10. Signal-to-noise $(S / N)$ response graph for unit weight of tested mixtures.

\subsection{Compressive Strength of Tested Mixtures}

The test results of the compressive strength of mixture specimens are shown in Table 9. It can be observed from the table that the compressive strengths of tested mixtures at $12 \mathrm{~h}$, 1 day and 28 days of age were between $0.02-0.62,0.2-1.49$, and $1.37-9.86 \mathrm{MPa}$, respectively. In addition, it can be seen from Figure 11 that the compressive strength of the M1-M3 mixtures without stone sludge at each age was generally lower, and the 28-day compressive strength of the age was between 1.37-2.13 MPa. The weight percentage of the stone sludge to replace the fine aggregates in the M4-M6 mixtures was 30\%. These mixtures had a higher compressive strength at all ages, and the 28-day compressive strength was between 8.56-9.86 MPa. The weight percentage of the stone sludge to replace the fine aggregates in the M7-M9 mixtures was $60 \%$. Their compressive strength at each age was roughly between the first two groups, and the compressive strength at 28 days was between 3.88 and 6.61 MPa. 
Table 9. Compressive strengths and the corresponding signal-to-noise ratio of tested mixtures.

\begin{tabular}{ccccccc}
\hline \multirow{2}{*}{ Mix No. } & \multicolumn{2}{c}{ Experimental Results (MPa) } & \multicolumn{2}{c}{ Corresponding $S / N$ Ratio (dB) } \\
\cline { 2 - 7 } & $\mathbf{1 2 ~ h}$ & One Day & 28 Days & $\mathbf{1 2} \mathbf{~ h}$ & One Day & 28 Days \\
\hline M1 & $0.24(0.04)$ & $0.52(0.05)$ & $1.78(0.03)$ & -12.25 & -5.68 & 4.98 \\
M2 & $0.10(0.01)$ & $0.33(0.03)$ & $2.13(0.07)$ & -20.00 & -9.58 & 6.55 \\
M3 & $0.02(0.01)$ & $0.20(0.02)$ & $1.37(0.23)$ & -34.42 & -13.81 & 2.73 \\
M4 & $0.59(0.02)$ & $1.49(0.05)$ & $9.86(0.18)$ & -4.63 & 3.46 & 19.88 \\
M5 & $0.52(0.05)$ & $1.39(0.01)$ & $8.69(0.43)$ & -5.75 & 2.84 & 18.78 \\
M6 & $0.62(0.04)$ & $1.47(0.09)$ & $8.56(0.14)$ & -4.15 & 3.35 & 18.65 \\
M7 & $0.59(0.05)$ & $1.19(0.07)$ & $6.61(0.32)$ & -4.66 & 1.49 & 16.40 \\
M8 & $0.55(0.01)$ & $1.01(0.02)$ & $5.83(0.31)$ & -5.19 & 0.09 & 15.31 \\
M9 & $0.33(0.02)$ & $0.65(0.02)$ & $3.88(0.12)$ & -9.68 & -3.68 & 11.77 \\
\hline
\end{tabular}

Note: Data in parentheses indicate standard deviation.

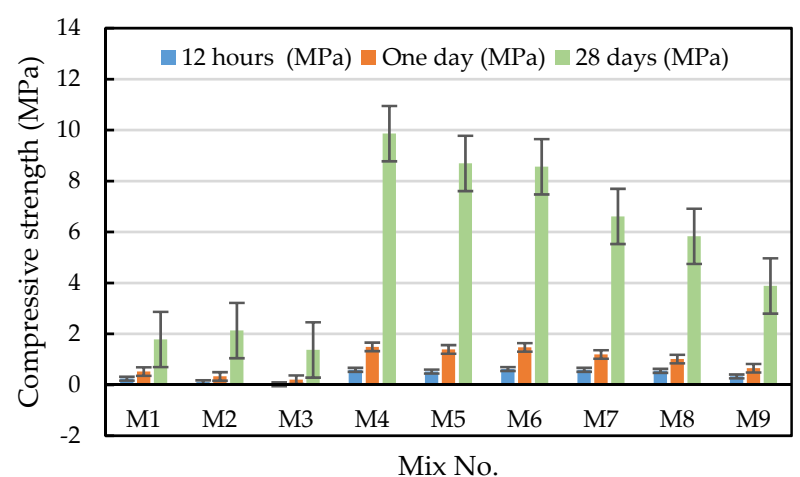

Figure 11. Compressive strength test results of tested mixtures.

On the other hand, in many cases, CLSM must be designed to have a strength equivalent to the surrounding soil after hardening, so that it can be used for future maintenance and excavation operations. Therefore, the excavability of hardened CLSM in the late age is an important consideration for many projects. In order to further understand the appropriateness of the harden properties of the prepared CLSM specimens, a comparison was made with the research results of other researchers, as shown in Table 6. It can be seen from Table 6 that the compressive strength results of this study were included in the scope of the existing literature. Taking the one-day compressive strength as an example, the results of this study ranged from 0.20 to $1.49 \mathrm{MPa}$, while the literature range was 0.04 to $1.67 \mathrm{MPa}$. In order to facilitate the subsequent construction of the paving layer, most of Taiwan's CLSM regulations require that the early strength of CLSM used for road trench backfilling be greater than $0.69 \mathrm{MPa}$. The results of the M4-M8 specimens in this study all met this requirement. As for the 28-day compressive strength, except for the M4 specimen, the 28-day compressive strength of the remaining specimens did not exceed $8.83 \mathrm{MPa}$, which was consistent with most of Taiwan's CLSM regulations. From this point of view, the compressive strength range of CLSM produced by using stone sludge could meet the needs of engineering operations.

The corresponding $S / N$ ratios of the compressive strength of mixture specimens is shown in Table 9 . Then, the $S / N$ ratios data in Table 9 are compiled into Table 10 to analyze the impact of each level of various experimental control factors on the compressive strengths of tested mixtures. On the other hand, the results of the ANOVA of the compressive strengths of tested mixtures are shown in Table 11. 
Table 10. Range analysis for compressive strengths of tested mixtures.

\begin{tabular}{|c|c|c|c|c|c|c|}
\hline \multirow{2}{*}{$\begin{array}{l}\text { Performance } \\
\text { Parameter }\end{array}$} & \multirow{2}{*}{$\begin{array}{l}\text { Experimental Control } \\
\text { Factor }\end{array}$} & \multicolumn{3}{|c|}{$\begin{array}{l}\text { Mean } S / N \text { Ratio } \\
(\eta, \text { Unit: dB) }\end{array}$} & \multirow{2}{*}{$\begin{array}{c}\text { Delta } \\
(\text { Max. } \eta-\text { Min. } \eta)\end{array}$} & \multirow{2}{*}{ Rank } \\
\hline & & Level 1 & Level 2 & Level 3 & & \\
\hline \multirow{4}{*}{$\begin{array}{l}\text { 12-h compressive } \\
\text { strength }\end{array}$} & Stone sludge dosage, A (\%) & -22.23 & -4.84 & -6.51 & 17.384 & 1 \\
\hline & Water-binder ratio, $\mathrm{B}$ & -7.18 & -10.31 & -16.09 & 8.908 & 2 \\
\hline & Accelerator dosage, C (\%) & -7.20 & -11.44 & -14.94 & 7.744 & 3 \\
\hline & LWA dosage, $\mathrm{D}\left(\mathrm{kg} / \mathrm{m}^{3}\right)$ & -9.23 & -9.60 & -14.75 & 5.521 & 4 \\
\hline \multirow{4}{*}{$\begin{array}{l}\text { One-day compressive } \\
\text { strength }\end{array}$} & Stone sludge dosage, A (\%) & -9.69 & 3.22 & -0.70 & 12.905 & 1 \\
\hline & Water-binder ratio, $\mathrm{B}$ & -0.24 & -2.22 & -4.71 & 4.466 & 2 \\
\hline & Accelerator dosage, C (\%) & -0.75 & -3.26 & -3.16 & 2.518 & 3 \\
\hline & LWA dosage, $\mathrm{D}\left(\mathrm{kg} / \mathrm{m}^{3}\right)$ & -2.17 & -1.58 & -3.42 & 1.842 & 4 \\
\hline \multirow{4}{*}{$\begin{array}{l}\text { 28-day compressive } \\
\text { strength }\end{array}$} & Stone sludge dosage, A (\%) & 4.76 & 19.10 & 14.49 & 14.347 & 1 \\
\hline & Water-binder ratio, B & 13.75 & 13.55 & 11.05 & 2.702 & 2 \\
\hline & Accelerator dosage, C (\%) & 12.98 & 12.73 & 12.64 & 0.345 & 4 \\
\hline & LWA dosage, $\mathrm{D}\left(\mathrm{kg} / \mathrm{m}^{3}\right)$ & 11.85 & 13.87 & 12.64 & 2.020 & 3 \\
\hline
\end{tabular}

Note: LWA = lightweight aggregate.

Table 11. Analysis of variance and $F$ test for compressive strengths of tested mixtures.

\begin{tabular}{|c|c|c|c|c|c|c|}
\hline $\begin{array}{c}\text { Performance } \\
\text { Parameter }\end{array}$ & $\begin{array}{c}\text { Experimental Control } \\
\text { Factor }\end{array}$ & $\begin{array}{c}\text { Sum of Square } \\
\left(S S_{Z}\right)\end{array}$ & $\begin{array}{c}\text { Degree of } \\
\text { Freedom }\end{array}$ & $\begin{array}{c}\text { Variation } \\
\left(M S_{Z}\right)\end{array}$ & $\begin{array}{c}F \text { Value } \\
\left(F_{Z}\right)\end{array}$ & $\begin{array}{c}\text { Percentage } \\
\text { Contribution }\left(P_{Z}\right)\end{array}$ \\
\hline \multirow{6}{*}{$\begin{array}{l}\text { 12-h compressive } \\
\text { strength }\end{array}$} & Stone sludge dosage, A (\%) & 551.93 & 3 & 183.98 & 9.67 & 60.22 \\
\hline & Water-binder ratio, B & 122.50 & 3 & 40.83 & 2.15 & 7.96 \\
\hline & Accelerator dosage, C (\%) & 90.22 & 3 & 30.07 & 1.58 & 31.82 \\
\hline & LWA dosage, $\mathrm{D}\left(\mathrm{kg} / \mathrm{m}^{3}\right)$ & 57.10 & 3 & 19.03 & 1.00 & 0.00 \\
\hline & All others/errors & 57.10 & 3 & 19.03 & - & - \\
\hline & Total & 821.75 & 12 & 273.92 & - & 100.00 \\
\hline \multirow{6}{*}{$\begin{array}{l}\text { One-day } \\
\text { compressive } \\
\text { strength }\end{array}$} & Stone sludge dosage, A (\%) & 262.68 & 3 & 87.56 & 49.49 & 82.97 \\
\hline & Water-binder ratio, $\mathrm{B}$ & 30.05 & 3 & 10.02 & 5.66 & 7.98 \\
\hline & Accelerator dosage, C (\%) & 12.17 & 3 & 4.06 & 2.29 & 9.06 \\
\hline & LWA dosage, $\mathrm{D}\left(\mathrm{kg} / \mathrm{m}^{3}\right)$ & 5.31 & 3 & 1.77 & 1.00 & 0.00 \\
\hline & All others/errors & 5.31 & 3 & 1.77 & - & - \\
\hline & Total & 310.21 & 12 & 103.40 & - & 100.00 \\
\hline \multirow{6}{*}{$\begin{array}{l}\text { 28-day } \\
\text { compressive } \\
\text { strength }\end{array}$} & Stone sludge dosage, A (\%) & 321.90 & 3 & 107.30 & 1693.26 & 94.10 \\
\hline & Water-binder ratio, $\mathrm{B}$ & 13.58 & 3 & 4.53 & 71.41 & 3.92 \\
\hline & Accelerator dosage, C (\%) & 0.19 & 3 & 0.06 & 1.00 & 0.22 \\
\hline & LWA dosage, $\mathrm{D}\left(\mathrm{kg} / \mathrm{m}^{3}\right)$ & 6.21 & 3 & 2.07 & 32.68 & 1.76 \\
\hline & All others/errors & 0.19 & 3 & 0.06 & - & - \\
\hline & Total & 341.88 & 12 & 113.96 & - & 100.00 \\
\hline
\end{tabular}

Note: LWA = lightweight aggregate.3.2.1. Twelve-Hour Compressive Strength.

For the compressive strength of tested mixtures, the objective function was a largerthe-better type. From the range analysis results in Table 10, in order to increase the 12-h compressive strength of CLSM, the order of importance of the control factors was the stone sludge dosage (factor A), the water-binder ratio (factor B), the accelerator dosage (factor C) and the lightweight aggregate dosage (factor D); the corresponding delta values were $17.384,8.908,7.744$ and 5.521, respectively. Moreover, the $S / N$ response graph for the compressive strength of tested mixtures is shown in Figure 12. When the use percentage of stone sludge decreased from $30 \%$ to $0 \%$, the $S / N$ ratio decreased significantly, which reflected a significant decrease in the 12-h compressive strength. Moreover, when the percentage of stone sludge usage increased from $30 \%$ to $60 \%$, the $S / N$ ratio decreased, which reflected a decrease in the 12-h compressive strength. In addition, as the waterbinder ratio increased, the $S / N$ ratio decreased significantly, which reflected a significant decrease in the 12-h compressive strength. Therefore, the stone sludge dosage had the greatest impact and was the main factor, while the water-binder ratio was the secondary 
factor. On the other hand, from the ANOVA results in Table 11, the most significant factor affecting the 12-h compressive strength was the stone sludge dosage, and its contribution percentage $\left(P_{Z}\right)$ was $60.22 \%$. The purpose of the prepared CLSM is to emphasize the need to increase the 12-h compressive strength; that is, the larger the compressive strength, the better. According to the experimental results, the optimal combination was $\mathrm{A}_{2} \mathrm{~B}_{3} \mathrm{C}_{1} \mathrm{D}_{2}$, and the 12-h compressive strength was $0.62 \mathrm{MPa}$. However, the best combination estimated by range analysis and ANOVA was $A_{2} B_{1} C_{1} D_{1}$, i.e., the stone sludge dosage at level 2, water-binder ratio at level 1 , accelerator dosage at level 1, and lightweight aggregate dosage at level 1.

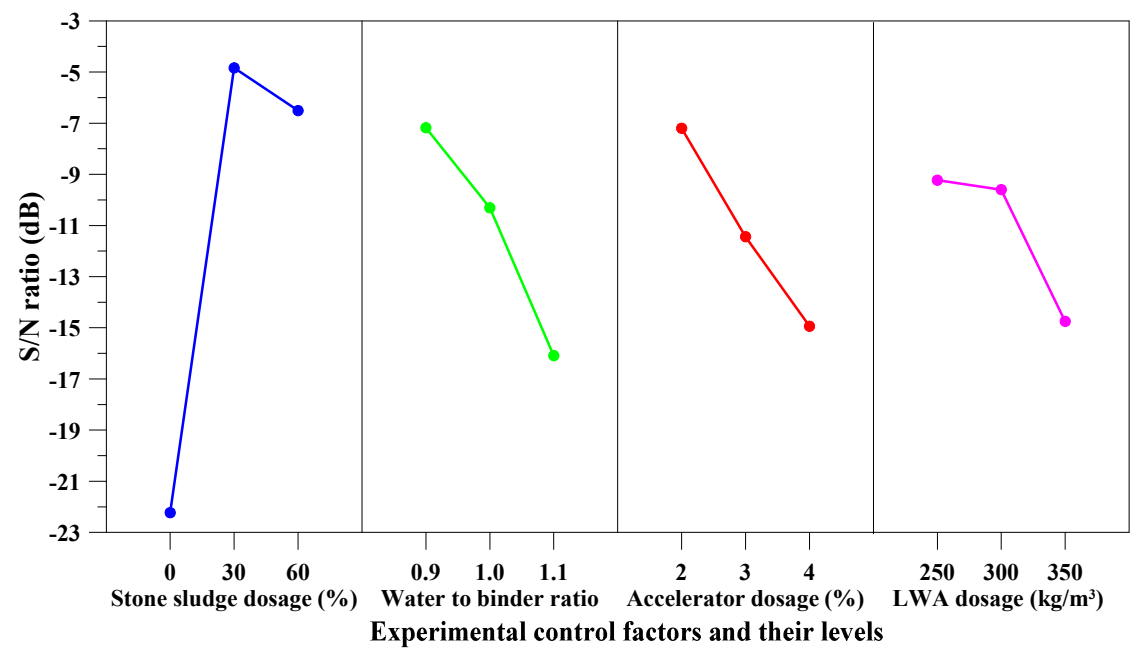

Figure 12. Signal-to-noise $(S / N)$ response graph for the 12-h compressive strength of tested mixtures.

\subsubsection{One-Day Compressive Strength}

From the range analysis results in Table 10, in order to increase the one-day compressive strength of CLSM, the order of importance of the control factors was the stone sludge dosage (factor A), the water-binder ratio (factor B), the accelerator dosage (factor C) and the lightweight aggregate dosage (factor D). The corresponding delta values were 12.905, $4.466,2.518$, and 1.842, respectively. This result is consistent with the result of the 12-h compressive strength. Moreover, the $S / N$ response graph for the one-day compressive strength of tested mixtures is shown in Figure 13. When the use percentage of stone sludge decreased from $30 \%$ to $0 \%$, the $S / N$ ratio decreased significantly, which reflected a significant decrease in the one-day compressive strength. Moreover, when the percentage of stone sludge usage increased from $30 \%$ to $60 \%$, the $S / N$ ratio decreased significantly, which reflected a significant decrease in one-day compressive strength. In addition, as the water-binder ratio increased, the $S / N$ ratio decreased significantly, which reflected a significant decrease in one-day compressive strength. Therefore, the stone sludge dosage had the greatest impact and was the main factor, while the water-binder ratio was the secondary factor. On the other hand, from the ANOVA results in Table 11, the most significant factor affecting the one-day compressive strength was the stone sludge dosage, and its contribution percentage $\left(P_{Z}\right)$ was $82.97 \%$. The purpose of the prepared CLSM is to emphasize the need to increase the one-day compressive strength. That is to say, the larger the one-day compressive strength, the better. According to the experimental results, the optimal combination was $\mathrm{A}_{2} \mathrm{~B}_{1} \mathrm{C}_{2} \mathrm{D}_{3}$, and the compressive strength was $1.49 \mathrm{MPa}$. However, the best combination estimated by range analysis and ANOVA was $A_{2} B_{1} C_{1} D_{2}$, i.e., stone sludge dosage at level 2 , water-binder ratio at level 1 , accelerator dosage at level 1 and lightweight aggregate dosage at level 2. 


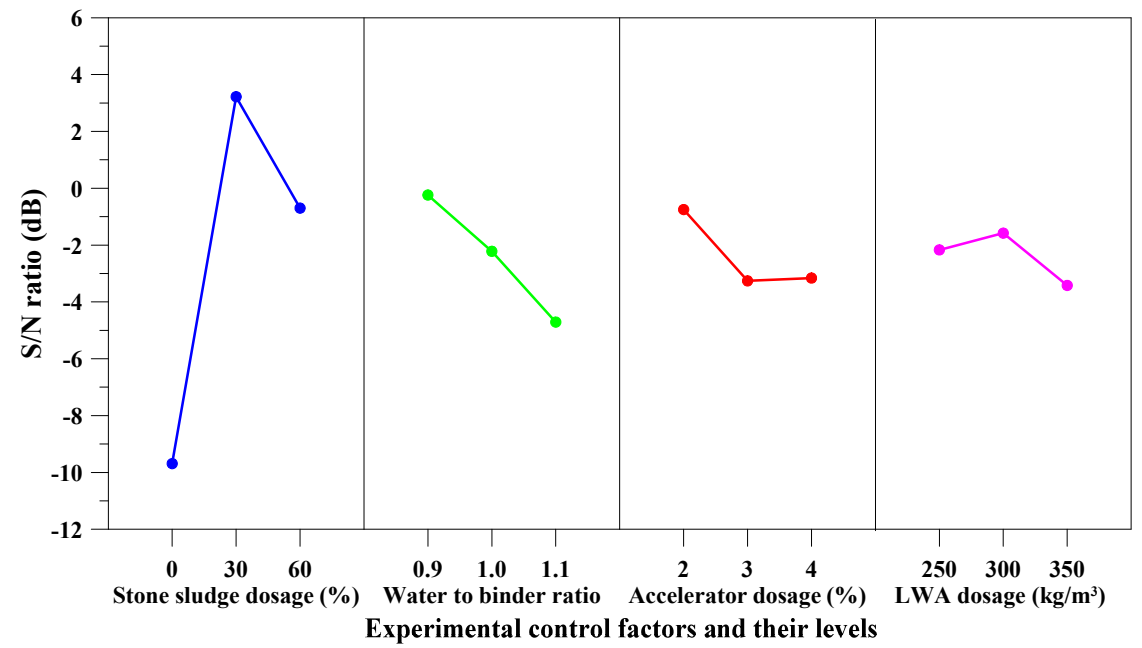

Figure 13. Signal-to-noise $(S / N)$ response graph for one-day compressive strength of tested mixtures.

\subsubsection{Twenty-Eight-Day Compressive Strength}

From the range analysis results in Table 10, in order to increase the 28-day compressive strength of CLSM, the order of importance of the control factors was the stone sludge dosage (factor A), the water-binder ratio (factor $\mathrm{B}$ ), the lightweight aggregate dosage (factor D) and the accelerator dosage (factor C); the corresponding delta values were 14.347, $2.702,2.020$ and 0.345 , respectively. Moreover, the $S / N$ response graph for the 28-day compressive strength of tested mixtures is shown in Figure 14. When the use percentage of stone sludge decreased from $30 \%$ to $0 \%$, the $S / N$ ratio decreased significantly, which reflected a significant decrease in the 28-day compressive strength. Moreover, when the percentage of stone sludge usage increased from $30 \%$ to $60 \%$, the $S / N$ ratio decreased significantly, which reflected a significant decrease in the 28-day compressive strength. In addition, as the water-binder ratio increased, the $S / N$ ratio decreased significantly, which reflected a significant decrease in the 28 -day compressive strength. Therefore, the stone sludge dosage had the greatest impact and was the main factor, while the water-binder ratio was the secondary factor. On the other hand, from the ANOVA results in Table 11, the most significant factor affecting the 28-day compressive strength was the stone sludge dosage, and its contribution percentage $\left(P_{Z}\right)$ was $94.1 \%$. The purpose of the prepared CLSM is to emphasize the need to increase the 28-day compressive strength. That is to say, the larger the 28-day compressive strength, the better. According to the experimental results, the optimal combination was $\mathrm{A}_{2} \mathrm{~B}_{1} \mathrm{C}_{2} \mathrm{D}_{3}$, and the compressive strength was $9.86 \mathrm{MPa}$. However, the best combination estimated by range analysis and ANOVA was $A_{2} B_{1} C_{1} D_{2}$, i.e., stone sludge dosage at level 2 , water-binder ratio at level 1 , accelerator dosage at level 1 , and lightweight aggregate dosage at level 2.

\subsection{Confirmation Test}

The results of this study show that in order to meet the requirements of most CLSM regulations in Taiwan that the early strength of CLSM used for road trench backfilling needs to be greater than $0.69 \mathrm{MPa}$, the percentage of stone sludge to replace fine aggregates can be $30 \%$. However, in order to facilitate future maintenance and excavation, the late strength development of CLSM should not be too great. As the percentage of stone sludge substituted for fine aggregates increased from $30 \%$ to $60 \%$, the compressive strength of CLSM at all ages decreased, and the 28-day compressive strength did not exceed $9 \mathrm{MPa}$. This indicates that stone sludge is a viable material for CLSM.

For various performance parameters, the experimental optimal combination and estimated optimal combination of CLSM prepared by this research are shown in Table 12. Of these, the experimental optimal combination of slump fluidity was consistent with the estimated optimal combination. The experimental optimal combination of other perfor- 
mance parameters was inconsistent with the estimated optimal combination. In order to verify that the best combination of experimental control factors can be obtained using the Taguchi method, four sets of confirmation test combinations were planned as shown in Table 12. It can be seen from Table 13 that the initial setting time of the confirmation test combination $\mathrm{A}_{2} \mathrm{~B}_{1} \mathrm{C}_{2} \mathrm{D}_{2}$ was $143 \mathrm{~min}$, which was shorter than the optimal combination of the experiment. The unit weight of the confirmation test combination $A_{1} B_{3} C_{1} D_{1}$ was $1950.2 \mathrm{~kg} / \mathrm{m}^{3}$, which was less than the optimal combination of the experiment. The 12-h compressive strength of the confirmation test combination $\mathrm{A}_{2} \mathrm{~B}_{1} \mathrm{C}_{1} \mathrm{D}_{1}$ was $0.78 \mathrm{MPa}$, which was higher than the experimental best combination. The one-day compressive strength of the confirmation test combination $\mathrm{A}_{2} \mathrm{~B}_{1} \mathrm{C}_{1} \mathrm{D}_{2}$ was $1.52 \mathrm{MPa}$, which was higher than the experimental best combination. The confirmation test results showed that the optimal combination of experimental control factors proposed by the Taguchi method could obtain the best results for the performance parameters.

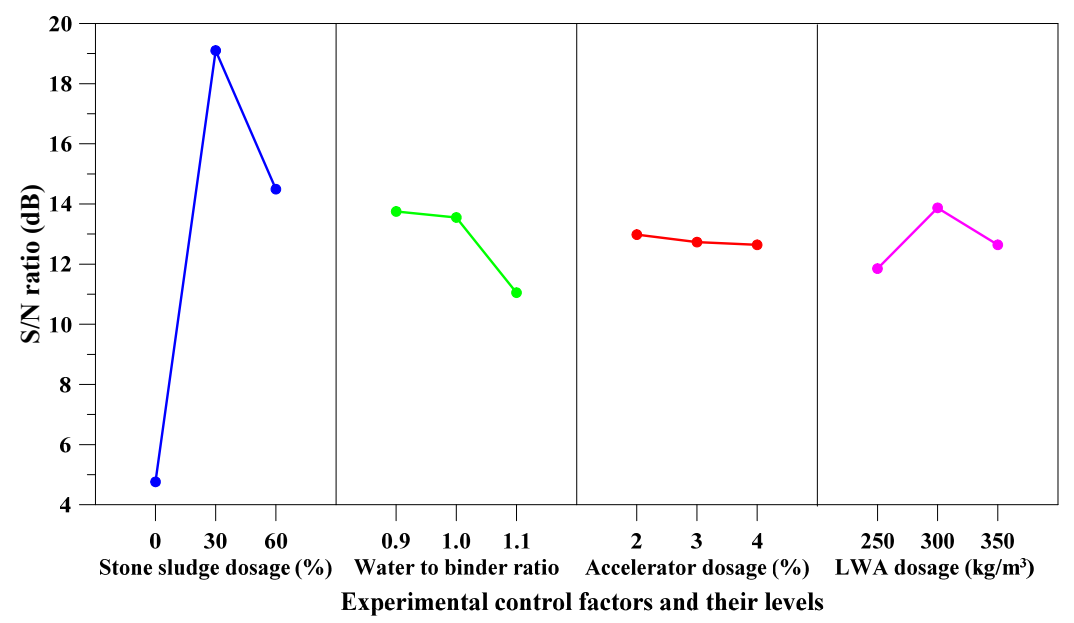

Figure 14. Signal-to-noise $(S / N)$ response graph for 28-day compressive strength of tested mixtures.

Table 12. Combinations of confirmation test.

\begin{tabular}{cccc}
\hline Performance Parameters & $\begin{array}{c}\text { Experimental Optimal } \\
\text { Combination }\end{array}$ & $\begin{array}{c}\text { Estimated Optimal } \\
\text { Combination }\end{array}$ & $\begin{array}{c}\text { Combinations of } \\
\text { Confirmation Test }\end{array}$ \\
\hline Initial setting time & $\mathrm{A}_{2} \mathrm{~B}_{3} \mathrm{C}_{1} \mathrm{D}_{2}$ & $\mathrm{~A}_{2} \mathrm{~B}_{1} \mathrm{C}_{2} \mathrm{D}_{2}$ & $\mathrm{~A}_{2} \mathrm{~B}_{1} \mathrm{C}_{2} \mathrm{D}_{2}$ \\
Unit weight & $\mathrm{A}_{1} \mathrm{~B}_{3} \mathrm{C}_{3} \mathrm{D}_{3}$ & $\mathrm{~A}_{1} \mathrm{~B}_{3} \mathrm{C}_{1} \mathrm{D}_{1}$ & $\mathrm{~A}_{1} \mathrm{~B}_{3} \mathrm{C}_{1} \mathrm{D}_{1}$ \\
12-h compressive strength & $\mathrm{A}_{2} \mathrm{~B}_{3} \mathrm{C}_{1} \mathrm{D}_{2}$ & $\mathrm{~A}_{2} \mathrm{~B}_{1} \mathrm{C}_{1} \mathrm{D}_{1}$ & $\mathrm{~A}_{2} \mathrm{~B}_{1} \mathrm{C}_{1} \mathrm{D}_{1}$ \\
One-day compressive strength & $\mathrm{A}_{2} \mathrm{~B}_{1} \mathrm{C}_{2} \mathrm{D}_{3}$ & $\mathrm{~A}_{2} \mathrm{~B}_{1} \mathrm{C}_{1} \mathrm{D}_{2}$ & $\mathrm{~A}_{2} \mathrm{~B}_{1} \mathrm{C}_{1} \mathrm{D}_{2}$ \\
\hline
\end{tabular}

Table 13. Results of confirmation test.

\begin{tabular}{|c|c|c|c|c|c|}
\hline Performance Parameters & $\begin{array}{l}\text { Experimental } \\
\text { Optimal } \\
\text { Combination }\end{array}$ & $\begin{array}{l}\text { Result of the } \\
\text { Optimal } \\
\text { Combination }\end{array}$ & $\begin{array}{l}\text { Combinations of } \\
\text { Confirmation Test }\end{array}$ & $\begin{array}{c}\text { Results of } \\
\text { Confirmation Test }\end{array}$ & $\begin{array}{l}\text { Standard } \\
\text { Deviation }\end{array}$ \\
\hline \multirow{4}{*}{$\begin{array}{c}\text { Initial setting time } \\
\text { Unit weight } \\
\text { 12-h Compressive Strength } \\
\text { One-day Compressive } \\
\text { Strength }\end{array}$} & $\mathrm{A}_{2} \mathrm{~B}_{3} \mathrm{C}_{1} \mathrm{D}_{2}$ & 159 (minute) & $\mathrm{A}_{2} \mathrm{~B}_{1} \mathrm{C}_{2} \mathrm{D}_{2}$ & 143 (minute) & - \\
\hline & $\mathrm{A}_{1} \mathrm{~B}_{3} \mathrm{C}_{3} \mathrm{D}_{3}$ & $1961.4\left(\mathrm{~kg} / \mathrm{m}^{3}\right)$ & $\mathrm{A}_{1} \mathrm{~B}_{3} \mathrm{C}_{1} \mathrm{D}_{1}$ & $1950.2\left(\mathrm{~kg} / \mathrm{m}^{3}\right)$ & - \\
\hline & $\mathrm{A}_{2} \mathrm{~B}_{3} \mathrm{C}_{1} \mathrm{D}_{2}$ & $0.62(\mathrm{MPa})$ & $\mathrm{A}_{2} \mathrm{~B}_{1} \mathrm{C}_{1} \mathrm{D}_{1}$ & $0.78(\mathrm{MPa})$ & $0.025(\mathrm{MPa})$ \\
\hline & $\mathrm{A}_{2} \mathrm{~B}_{1} \mathrm{C}_{2} \mathrm{D}_{3}$ & $1.49(\mathrm{MPa})$ & $\mathrm{A}_{2} \mathrm{~B}_{1} \mathrm{C}_{1} \mathrm{D}_{2}$ & $1.52(\mathrm{MPa})$ & $0.04(\mathrm{MPa})$ \\
\hline
\end{tabular}

\subsection{Cost Analysis of Production CLSM with Stone Sludge and Lightweight Aggregates}

This research aimed to produce and characterize low-density CLSM using stone sludge. There were four parameters selected in this study and each had three levels, which were the amount of stone sludge $(0 \%, 30 \%$, and $60 \%)$, the water-binder ratio $(0.9,1.0$ and 
1.1), the amount of accelerator $(2 \%, 3 \%$, and $4 \%)$ and the amount of lightweight aggregate $(250,300$ and $350 \mathrm{~kg}$ per cubic meter). Considering the performance of the fresh properties, compressive strength, utilization rate of renewable resources and economy, the following mixture design of the large-scale production CLSM containing stone sludge was selected: a water-binder ratio of 1.1, an amount of accelerator agent of $3 \%$, replacement of $60 \%$ fine aggregates with stone sludge and a lightweight aggregate content of $250 \mathrm{~kg}$ per cubic meter. These mixture proportions had a higher amount of stone sludge, and the mechanical performance could also meet the requirements of CLSM.

Table 14 shows the unit price of various materials required for the production of CLSM. The processing fee of stone sludge is currently NT $\$ 1000-1500$ per ton because it is a general industrial waste. Therefore, the unit price of stone sludge in the table is NT\$-1.0/ $\mathrm{kg}$, which means that the cost can be reduced. The unit price of general commercial CLSM in Taiwan varies from region to region, and the price per cubic meter applied to public works ranges from NT $\$ 1230$ to NT $\$ 2200$. Table 14 shows the mix proportions and material cost analysis of ordinary CLSM and stone sludge CLSM. The material cost per cubic meter of ordinary CLSM is about NT\$1777.3. The material cost of stone sludge CLSM is NT\$697.8 per cubic meter. The material cost per cubic meter of stone sludge CLSM is about NT $\$ 1079.5$ lower than that of ordinary public works CLSM, which can reduce the cost by $60.7 \%$. In terms of economy, the production of CLSM from stone sludge is indeed quite competitive.

\subsection{The Sustainability Effect of CLSM with Stone Sludge and Lightweight Aggregates}

In Taiwan, it is quite common to use slices of stone such as marble or granite as decoration materials for building structures. However, the stone sludge produced by stone slicing in Taiwan exceeds one million metric tons every year. The sludge produced by cutting is extremely small and has a high-water content, which causes great trouble in the terminal disposal. At present, only a small part of it was recycled into raw cement, and most of it became earthwork. The amount of stone sludge that has not been reused and piled-up is already huge, which has caused an environmental burden in Taiwan. On the other hand, Taiwan's sludge treatment regulations are becoming stricter, and the cost of sludge disposal is gradually increasing. Therefore, stone sludge must be managed from the source, recycled and reused, and strengthened in the final treatment and management, so that the stone sludge can be reduced, stabilized, harmless, and recycled, thereby avoiding secondary pollution.

Although the definition of sustainability has not yet been consistent, it is usually defined as the process and action by which humans avoid the depletion of natural resources to maintain ecological balance without reducing the quality of life in modern society. Especially, it is composed of economy, society, and environment. Taiwan is small in area, densely populated, and limited land resources. In the face of the difficulty of finding disposal sites, reducing waste production and recycling resources utilization has become an important direction for current disposal. For this, in order to achieve the purpose of sustainable environmental management, the disposal and reuse methods of stone sludge need to be developed urgently.

Since CLSM is mostly used in backfill sites that require re-excavation, the required strength is not high for the purpose of continuous re-excavation. In view of this, the Taiwanese government encourages the use of recycled materials to manufacture CLSM. In this study, the back-end waste (i.e., stone sludge) produced by stone cutting was reused as a renewable material in CLSM. Its appearance is not much different from the general CLSM, as shown in Figure 15. From the test results and economic cost analysis, the use of stone sludge to produce CLSM could not only achieve waste recycling, but also had economic feasibility. These results also showed that waste reduction and resource disposal could be achieved, and the number of fine aggregates used could also be reduced. In other words, the production of CLSM with stone sludge as a raw material could reduce the impact of carbon emissions on the environment, thereby achieving the goal of environmental sustainability. 
Table 14. Unit price of controlled low-strength material (CLSM) materials and cost analysis of CLSM.

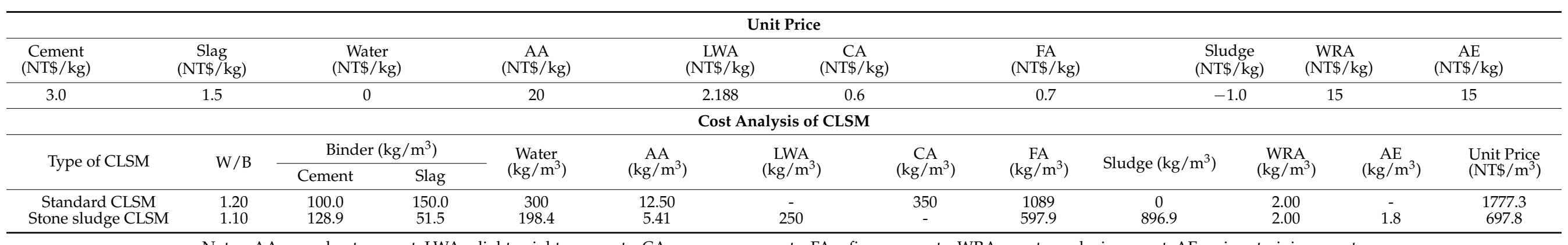

Notes: $\mathrm{AA}=$ accelerator agent; $\mathrm{LWA}=$ lightweight aggregate; $\mathrm{CA}=$ coarse aggregate; $\mathrm{FA}=$ fine aggregate; $\mathrm{WRA}=$ water-reducing agent; $\mathrm{AE}=$ air-entraining agent. 


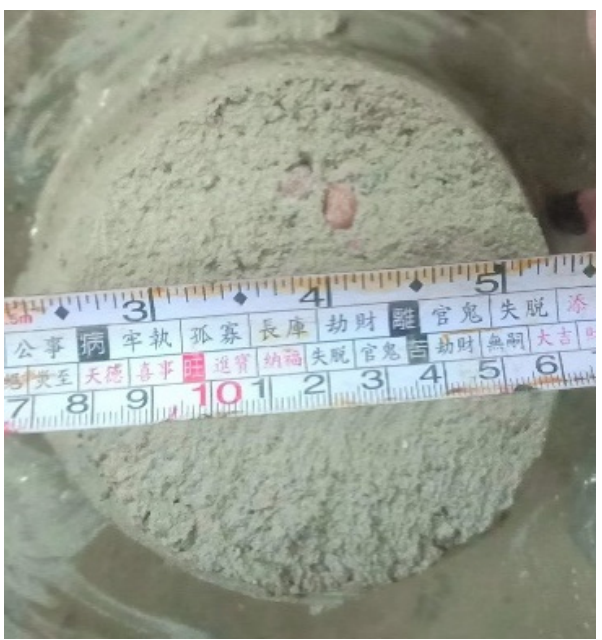

(a)

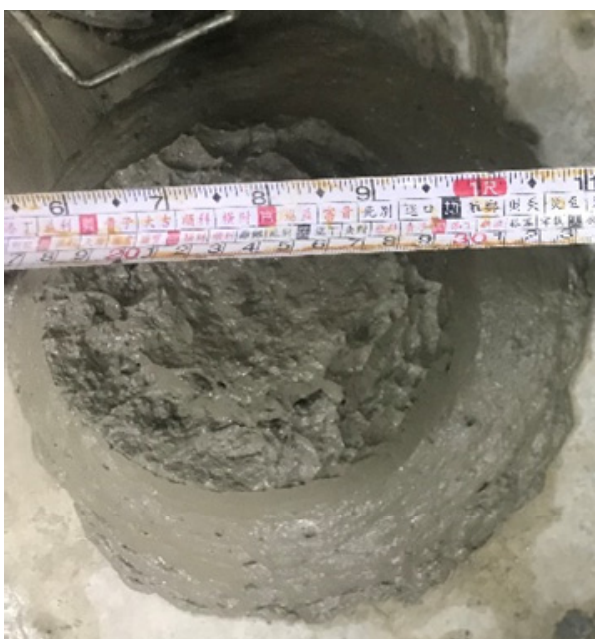

(b)

Figure 15. Appearance of CLSM samples: (a) CLSM produced by stone sludge and (b) CLSM produced by reservoir sediments.

\section{Conclusions}

In this study, dimension stone sludge was used to replace fine aggregates, and lightweight aggregates were used to replace ordinary coarse aggregates to explore the feasibility of producing low-density CLSM. The test results showed that the use of stone sludge and lightweight aggregates to produce low-density CLSM was extremely feasible. Based on the aforementioned test results and analysis, the following conclusions can be drawn.

The increase in the percentage of stone sludge to replace fine aggregates prolonged the setting time. Moreover, at the age of 28 days, the compressive strength of most specimens did not exceed the upper limit of $8.83 \mathrm{MPa}$ stipulated by Taiwan's Public Construction Commission.

In view of the various engineering requirements of CLSM, the Taguchi method can be used for optimizing the process parameters of producing controlled low-strength materials by using dimension stone sludge and lightweight aggregates. When reducing the unit weight of CLSM, the order of importance of the control factors was the stone sludge dosage, the lightweight aggregate dosage, the water-binder ratio, and the accelerator dosage. Moreover, the ANOVA results showed that the most significant factor affecting the unit weight was the stone sludge dosage, and its contribution percentage was $90.95 \%$.

For the improvement of the 12-h compressive strength of CLSM, the order of importance of the control factors was the stone sludge dosage, the water-binder ratio, the accelerator dosage and the lightweight aggregate dosage. In addition, the ANOVA results showed that the most significant factor affecting the compressive strength was the stone sludge dosage, and its contribution percentage was $60.22 \%$.

Considering the performance of the fresh properties, compressive strength, utilization rate of renewable resources and economy, the following mixture design of the large-scale production CLSM containing stone sludge was selected: a water-binder ratio of 1.1, an amount of accelerator agent of 3\%, replacement of $60 \%$ fine aggregates with stone sludge, and a lightweight aggregate content of $250 \mathrm{~kg} / \mathrm{m}^{3}$. These mixture proportions had a higher amount of stone sludge, and the mechanical performance could also meet the requirements of CLSM. The material cost per cubic meter of stone sludge CLSM is about NT\$1079.5 lower than that of ordinary public works CLSM, which can reduce the cost by $60.7 \%$. In economic terms, the production of CLSM from stone sludge is indeed quite competitive. 
Author Contributions: Conceptualization, H.-J.C. and C.-W.T.; methodology, H.-J.C. and C.-W.T.; software, C.-W.T.; validation, H.-C.L. and C.-W.T.; formal analysis, C.-W.T.; investigation, H.-C.L. and C.-W.T.; resources, C.-W.T.; data curation, H.-J.C. and C.-W.T.; writing-original draft preparation, H.-J.C. and C.-W.T.; writing-review and editing, C.-W.T.; visualization, C.-W.T.; supervision, C.-W.T.; project administration, C.-W.T.; funding acquisition, C.-W.T. All authors have read and agreed to the published version of the manuscript.

Funding: This research was funded by the Ministry of Science and Technology of Taiwan grant number MOST 108-2622-E-230-003-CC3.

Institutional Review Board Statement: Not applicable.

Informed Consent Statement: Not applicable.

Data Availability Statement: The data presented in this study are available on request from the corresponding author.

Acknowledgments: The authors are grateful to the Department of Civil Engineering of National Chung-Hsing University for providing experimental equipment and technical support.

Conflicts of Interest: The authors declare no conflict of interest.

\section{References}

1. An Official Website of the European Union. Available online: https:/ / ec.europa.eu/environment/index_en (accessed on 24 April 2021).

2. Resource Recycling Act. Available online: http://law.epa.gov.tw/zh-tw/laws/962396701.html (accessed on 24 April 2021).

3. 229R-13 Report on Controlled Low-Strength Materials; ACI Committee 229; American Concrete Institute: Farmington Hills, MI, USA, 2013.

4. Study on the Application of Controlled Low-Strength Materials in Civil. Engineering; Construction and Planning Agency, Ministry of the Interior: Taiwan, 2002.

5. Adaska, W.S. Controlled low strength materials. Concr. Int. 1997, 19, 41-43.

6. Funston, J.J.; Krell, W.C.; Zimmer, F.V. Flowable fly ash, a new cement stabilized backfill. Civ. Eng. ASCE 1984, 4, 22-26.

7. The Design and Application of Controlled Low Strength Material (Flowable Fill); ASTM STP 1331; Howard, A.K.; Hitch, A.K.J.L. (Eds.) ASTM: West Conshohocken, PA, USA, 1998; ASTM STP 1331.

8. Graziani, A.; Giovannelli, G. Materiali da Costruzione i Lapidei Struttura del Settore e Tendenze Innovative; Centro Studi Osservatorio Fillea Grandi Imprese e Lavoro: Roma, Italy, 2015.

9. Chen, P.L. Reuse of Stone Sludge in Control Low Strength Material. Master's Thesis, Department of Civil Engineering \& Environmental Resource Management, Dahan Institute of Technology, Taiwan, 2014.

10. Martínez-García, R.; de Rojas, M.I.S.; Morán de Pozo, J.M.; Fraile-Fernández, F.J.; Juan-Valdés, A. Evaluation of Mechanical Characteristics of Cement Mortar with Fine Recycled Concrete Aggregates (FRCA). Sustainability 2021, 13, 414. [CrossRef]

11. López Boadella, Í.; López Gayarre, F.; Suárez González, J.; Gómez-Soberón, J.M.; López-Colina Pérez, C.; Serrano López, M.; de Brito, J. The Influence of Granite Cutting Waste on The Properties of Ultra-High Performance Concrete. Materials 2019, 12, 634. [CrossRef] [PubMed]

12. Zamora-Castro, S.A.; Salgado-Estrada, R.; Sandoval-Herazo, L.C.; Melendez-Armenta, R.A.; Manzano-Huerta, E.; Yelmi-Carrillo, E.; Herrera-May, A.L. Sustainable Development of Concrete through Aggregates and Innovative Materials: A Review. Appl. Sci. 2021, 11, 629. [CrossRef]

13. Chen, H.J.; Yang, Y.; Tang, C.W.; Wang, S.Y. Producing synthetic lightweight aggregates from reservoir sediments. Constr. Build. Mater. 2012, 28, 387-394. [CrossRef]

14. Chen, H.J.; Hsueh, Y.C.; Peng, C.F.; Tang, C.W. Paper Sludge Reuse in Lightweight Aggregates Manufacturing. Materials 2016, 9, 876. [CrossRef]

15. Chen, H.J.; Chang, S.N.; Tang, C.W. Application of the Taguchi Method for Optimizing the Process Parameters of Producing Lightweight Aggregates by Incorporating Tile Grinding Sludge with Reservoir Sediments. Materials 2017, 10, 1294. [CrossRef]

16. Naik, T.R.; Kraus, R.N.; Siddique, R. Controlled low-strength materials containing mixtures of coal ash and new pozzolanic materials. ACI Mater. J. 2003, 100, 208-215.

17. Lachemi, M.; Hossain, K.M.A.; Shehata, M.; Thaha, W. Controlled low strength materials incorporating cement kiln dust from various sources. Cem. Concr. Compos. 2008, 30, 381-392. [CrossRef]

18. Shon, C.S.; Mukhopadhyay, A.K.; Saylak, D.; Zollinger, D.G.; Mejeoumov, G.G. Potential use of stockpiled circulating fluidized bed combustion ashes in controlled low strength material (CLSM) mixture. Constr. Build. Mater. 2010, 24, 839-847. [CrossRef]

19. Lin, W.T.; Weng, T.L.; Cheng, A.; Chao, S.J.; Hsu, H.M. Properties of Controlled Low Strength Material with Circulating Fluidized Bed Combustion Ash and Recycled Aggregates. Materials 2018, 11, 715. [CrossRef] [PubMed]

20. Kuo, W.T.; Gao, Z.C. Engineering Properties of Controlled Low-Strength Materials Containing Bottom Ash of Municipal Solid Waste Incinerator and Water Filter Silt. Appl. Sci. 2018, 8, 1377. [CrossRef] 
21. Wu, H.; Huang, B.; Shu, X.; Yin, J. Utilization of solid wastes/byproducts from paper mills in Controlled Low Strength Material (CLSM). Constr. Build. Mater. 2016, 118, 155-163. [CrossRef]

22. Park, S.M.; Lee, N.K.; Lee, H.K. Circulating fluidized bed combustion ash as controlled low-strength material (CLSM) by alkaline activation. Constr. Build. Mater. 2017, 156, 728-738. [CrossRef]

23. Jang, J.G.; Park, S.M.; Chung, S.; Ahn, J.W.; Kim, H.K. Utilization of circulating fluidized bed combustion ash in producing controlled low-strength materials with cement or sodium carbonate as activator. Constr. Build. Mater. 2018, 159, 642-651. [CrossRef]

24. Kuo, W.T.; Wang, H.Y.; Shu, C.Y.; Su, D.S. Engineering properties of controlled low-strength materials containing waste oyster shells. Constr. Build. Mater. 2013, 46, 128-133. [CrossRef]

25. Mneina, A.; Solimanb, A.M.; Ahmed, A.; El Naggar, M.H. Engineering properties of controlled low-strength materials containing treated oil sand waste. Constr. Build. Mater. 2018, 159, 277-285. [CrossRef]

26. Wang, L.; Zou, F.; Fang, X.; Tsang, D.C.W.; Poon, C.S.; Leng, Z.; Baek, K. A novel type of controlled low strength material derived from alum sludge and green materials. Constr. Build. Mater. 2018, 165, 792-800. [CrossRef]

27. Fang, X.; Wang, L.; Poon, C.S.; Baek, K.; Tsang, D.C.W.; Kwokc, S.K. Transforming waterworks sludge into controlled low-strength material: Bench-scale optimization and field test validation. J. Environ. Manag. 2019, 232, 254-263. [CrossRef]

28. Tang, C.W.; Cheng, C.K. Partial Replacement of Fine Aggregate using Water Purification Sludge in Producing CLSM. Sustainability 2019, 11, 1351. [CrossRef]

29. Hung, C.C.; Wang, C.C.; Wang, H.Y. Establishment of the Controlled Low-Strength Desulfurization Slag Prediction Model for Compressive Strength and Surface Resistivity. Appl. Sci. 2020, 10, 5674. [CrossRef]

30. Park, J.; Hong, G. Strength Characteristics of Controlled Low-Strength Materials with Waste Paper Sludge Ash (WPSA) for Prevention of Sewage Pipe Damage. Materials 2020, 13, 4238. [CrossRef] [PubMed]

31. El-Hinnawi, E.; Abayazeed, S.D. Characterization of Dimension Stone Sawing Sludge in Egypt. J. Appl. Sci. 2011, 11. [CrossRef]

32. Method of Slump Test for Concrete; Chinese National Standard (CNS) 1176; The Bureau of Standards, Metrology and Inspection (BSMI); The Ministry of Economic Affairs (MOEA): Taipei, Taiwan, 2003.

33. Method of test for Slump Flow of High Flowing Concrete; Chinese National Standard (CNS) 14842; The Bureau of Standards, Metrology and Inspection (BSMI); The Ministry of Economic Affairs (MOEA): Taipei, Taiwan, 2004.

34. Standard Test Method for Time of Setting of Concrete Mixtures by Penetration Resistance; ASTM C403/C403M-16; ASTM International: West Conshohocken, PA, USA, 2016; Available online: https://www.astm.org/Standards/C403 (accessed on 1 April 2021).

35. Standard Test. Method for Density (Unit Weight), Yield, Cement Content, and Air Content (Gravimetric) of Controlled Low-Strength Material (CLSM); ASTM D6023-16; ASTM International: West Conshohocken, PA, USA, 2016; Available online: https://www. astm.org/Standards/D6023.htm (accessed on 1 April 2021).

36. Method of Test for Compressive Strength of Cylindrical Concrete Specimens; Chinese National Standard (CNS) 1232; The Bureau of Standards, Metrology and Inspection (BSMI); The Ministry of Economic Affairs (MOEA): Taipei, Taiwan, 2002.

37. Taguchi, G. Introduction to Quality Engineering: Designing Quality into Products and Processes; Asian Productivity Organization: Tokyo, Japan, 1987.

38. Neville, A.M. Properties of Concrete; Longman: Harlow, UK, 1994.

39. Tang, C.W. Properties of fired bricks by incorporating TFT-LCD waste glass powder with reservoir sediments. Sustainability 2018, 10, 2503. [CrossRef]

40. Kaliyavaradhan, S.K.; Ling, T.C.; Guo, M.Z.; Mo, K.H. Waste resources recycling in controlled low-strength material (CLSM): A critical review on plastic properties. J. Environ. Manag. 2019, 241, 383-396. [CrossRef]

41. Trejo, D.; Folliard, K.J.; Du, L. Sustainable Development Using Controlled Low-Strength Material. In Proceedings of the International Workshop on Sustainable Development and Concrete Technology, Beijing, China, 20-21 May 2004; pp. 231-250.

42. Do, T.M.; Kim, Y.S. Engineering properties of controlled low strength material (CLSM) incorporating red mud. Geo-Engineering 2016, 7, 1-17. [CrossRef]

43. Razak, H.A.; Naganathan, S.; Hamid, S.N.A. Performance appraisal of industrial waste incineration bottom ash as controlled low-strength material. J. Hazard. Mater. 2009, 172, 862-867. [CrossRef]

44. Türkel, S. Strength properties of fly ash based controlled low strength materials. J. Hazard. Mater. 2007, 147, 1015-1019. [CrossRef]

45. Taha, R.A.; Alnuaimi, A.S.; Al-Jabr, K.S.; Al-Harthy, A.S. Evaluation of controlled low strength materials containing industrial by-products. Build. Environ. 2007, 42, 3366-3372. [CrossRef] 